\title{
Synthesis and applications of fluorescent-tagged scale inhibitors in water treatment. A review
}

\author{
M. Oshchepkov, ${ }^{1,2}$ S. Tkachenko ${ }^{1,2}$ and K. Popov ${ }^{1 *}$ \\ 'JSC "Fine Chemicals R\&D Centre", Krasnobogatyrskaya 42, str. 1, 107258 Moscow, \\ Russian Federation \\ ${ }^{2}$ Mendeleev University of Chemical Technology of Russia, Miusskaya sq. 9, 125047 \\ Moscow, Russian Federation \\ *E-mail:ki-popov49@yandex.ru
}

\begin{abstract}
Fluorescent-tagged scale inhibitor application is a new trend in water treatment. An increasing interest to the fluorescent antiscalants is associated with a need of a better scale inhibitor concentration control in industrial applications: the concentration of antiscalants in the circulating system is usually changed by evaporation of water, reagent sorption on the pipe surfaces and on scale particles, as well as by a periodical discharge of the circulating water with some deposit. This paper considers synthesis, properties and industrial applications of antiscalants bearing a fluorescent fragment. A special focus is done on the covalent implementation of the fluorescent fragment into the polymer matrix, performed in two different ways: (a) the first one includes attachment along with the polymer formation process; (b) the second one is based on the fluorophore binding to the ready-made polymer matrix. An attachment of a fluorescent fragment to the bisphosphonate is also described. Besides the issues of antiscalant concentration monitoring in industrial facilities, the unique opportunity of the scale inhibition theory development via the direct visualization of fluorescent-tagged scale inhibitors in various scale formation processes is demonstrated. A recent progress in scale inhibition mechanism understanding due to an antiscalant visualization in situ is highlighted.
\end{abstract}

Key words: visualization, fluorescent-tagged bisphosphonate, gypsum, scale formation, mechanisms of scale inhibition, crystal formation.

Received: March 15, 2019. Published: July 1, 2019

doi: $\underline{10.17675 / 2305-6894-2019-8-3-2}$

\section{Introduction}

Fluorescent-tagged scale inhibitor application is a new trend in water treatment $[1,2]$. In 1992 the Nalco Chemical Company first patented an implementation of a fluorescent fragment into the polymeric scale inhibitor [3], Figure 1a. This communication was soon followed by numerous patents issued by Nalko [4-7], Rhodia Chimie [8,9], Kemira Chemicals Inc. [10-12], Ecolab USA Inc. [13, 14], PJSC "Fine Chemicals R\&D Centre" [15] and by several universities and research centers of Republic of China [16-20], as well as by research reports [2, 21-36]. In 2019 the first communication on synthesis and applications of a fluorescent-tagged phosphonate scale inhibitor - 1-hydroxy-7-(6-methoxy- 
1,3-dioxo-1H-benzo[de]isoquinolin-2(3H)-yl)heptane-1,1-diyl-di(phosphonic acid), (HEDPF) was published [37], Figure 1b. The most common fluorescent fragments used for attachment are presented in Figure 2.

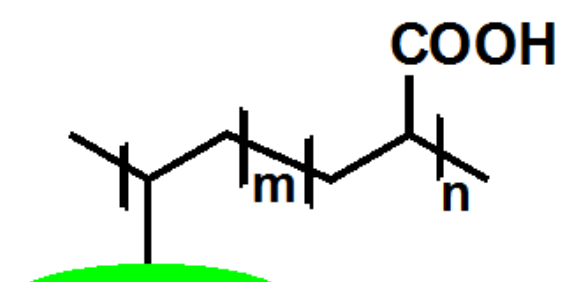

Fluorophore

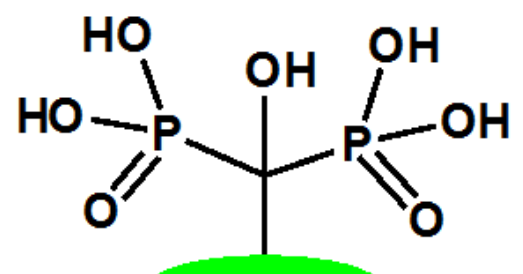

Fluorophore

b

Figure 1. The chemical structures of florescent-tagged antiscalants: polycarboxylates (a) and phosphonates (b)

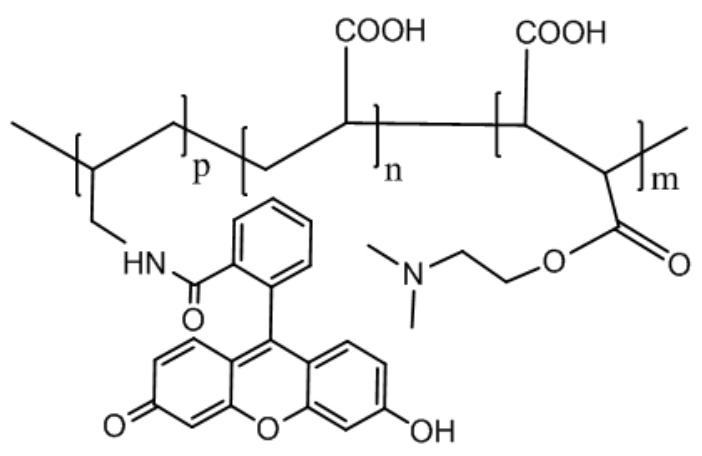

a

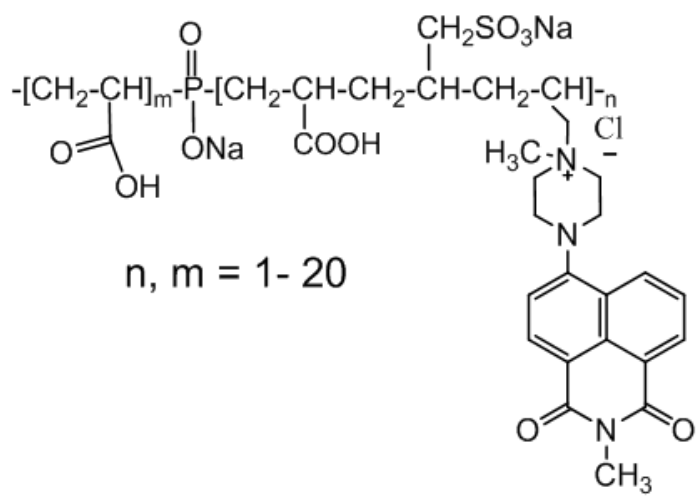

b

Figure 2. The chemical structures of florescent-tagged antiscalans: fluorescein (a) and 1,8-naphthalimide (b) derivatives.

Most of publications in the field arrived over the last decade. An increasing interest to the fluorescent antiscalants is associated with a need of a better scale inhibitor concentration control in industrial applications: oilfield and reverse osmosis facilities, boilers, heat exchangers, evaporation plants etc. Indeed, the concentration of antiscalants in the circulating system is usually changed by evaporation of water, reagent sorption on the pipe surfaces and scale particles, and by a periodical discharge of the circulating water with some deposit. Therefore, an adequate monitoring of the polymer concentration is needed to minimize the consumptions of both scale inhibitor and water. The conventional monitoring methods based on UV-VIS, potentiometry, etc. [38-43] do not permit to arrange an "on line" measurements for polyacrylates and phosphonates. Besides, those that are 
intended to control polymers [38-42] have a very arbitrary reliability relative to the phoshonate detection methods [43, 44].

Recently the situation with antiscalant monitoring becomes worth. The easily controlled phosphonates are steadily substituted by the "environmentally friendly" biodegradable antiscalants, such as polymaleates (PMA), polyaspartates (PASP), polyepoxysuccinates (PESA), [45, 46]. Although, the organophosphonates are dominating recently at the world market, the environmental concerns and discharge limitations have forced the scale-inhibitor chemistry to move toward "green antiscalants" that are readily biodegradable and have minimal environmental impact. Indeed, phosphorus-based inhibitors are hardly biodegradable. These reagents persist for many years after their disposal, which leads to eutrophication problems. Phosphorus discharges are, therefore, regulated in many countries worldwide, and permissible limits are constantly decreasing [46]. However, the reliable analytical methods of the "green" scale inhibitors monitoring in industry are missing. In this relevance the intensity of fluorescence emitted from a covalently bound to polymer tracer becomes a matter of choice [1].

Fluorescence is the emission of light by a substance that has absorbed light with a different wavelength or electromagnetic radiation. It has recently many practical and valuable applications, including mineralogy, gemology, medicine, chemical sensors (fluorescence spectroscopy), fluorescent labeling, dyes, biological detectors, environmental monitoring, cosmic-ray detection, and, most commonly, fluorescent lamps [1]. In the field of water treatment this technique may provide a unique opportunity of "on line" in situ monitoring of an antiscalant concentration. Meanwhile, this approach has also some restrictions and drawbacks. Thus, the main objective of a present review is to analyze the feasibility of a scale inhibitor fluorescent marker application in the real water treatment industrial facilities. For example, EMEC company measurement system for determination of the concentration of a fluorescent labeled reagent for circulating cooling systems (ETRC - single channel flow fluorometer) has the following characteristics: operating range $<1-300 \mathrm{ppb}$, sensitivity $<1 \mathrm{ppb}$, timespan to the operation mode takes 5 seconds, Figure 3.

However, there is another and perhaps even more promising field of the fluorescenttagged antiscalants application: the visualization of antiscalant on scale cores, reverse osmosis membranes, engineering equipment surfaces. The first publication on the taskspecific fluorescent-tagged scale inhibitor location on gypsum crystals in 2019 revealed a necessity of recent scale inhibition theory revision [37]. Therefore, another objective of a present review is to present horizons of scaling process visualization in presence of fluorescent-tagged inhibitors. 


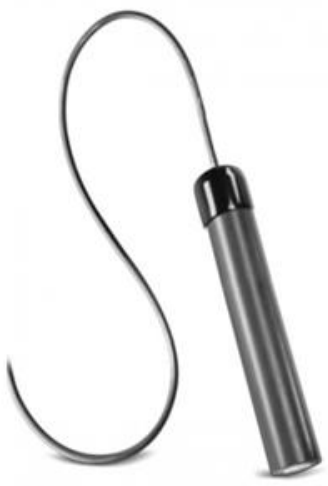

A Single-channel flow fluorometer (ETRC)

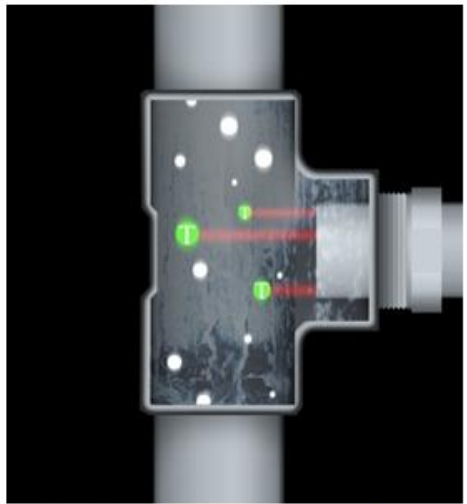

The ETRC sensor operating principle

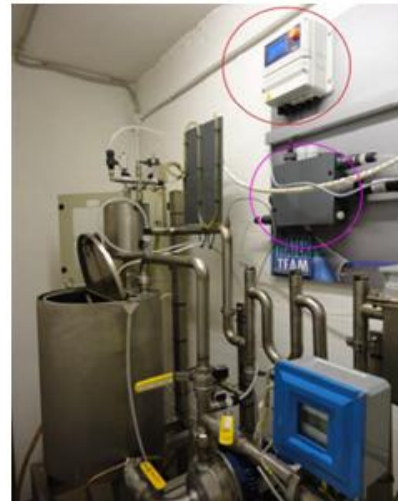

A fragment of water cycle with built-in sensor and controller

Figure 3. Industrial devices for a fluorescent marker monitoring.

\section{Synthesis}

\subsection{Fluorescent-tagged polymers}

Covalent implementation of the fluorescent fragment into the polymer matrix can be performed in two different ways: (a) the first one includes attachment along with the polymer formation process; (b) the second one is based on the fluorophore binding to the ready-made polymer matrix [1].

Besides, the polymer itself may have fluorescence without any specially introduced fluorescent fragments [47]. Thus, there is no need to modify it with special markers. The inhibitor is easily prepared by the following method: chitosan is depolymerized with sodium nitrite $\left(6 \%\right.$ acetic acid, $25^{\circ} \mathrm{C}, 3$ hours $)$, followed by reductive treatment with $\mathrm{NaBH}_{4}\left(25^{\circ} \mathrm{C}, \mathrm{pH}=7\right)($ Scheme 1).
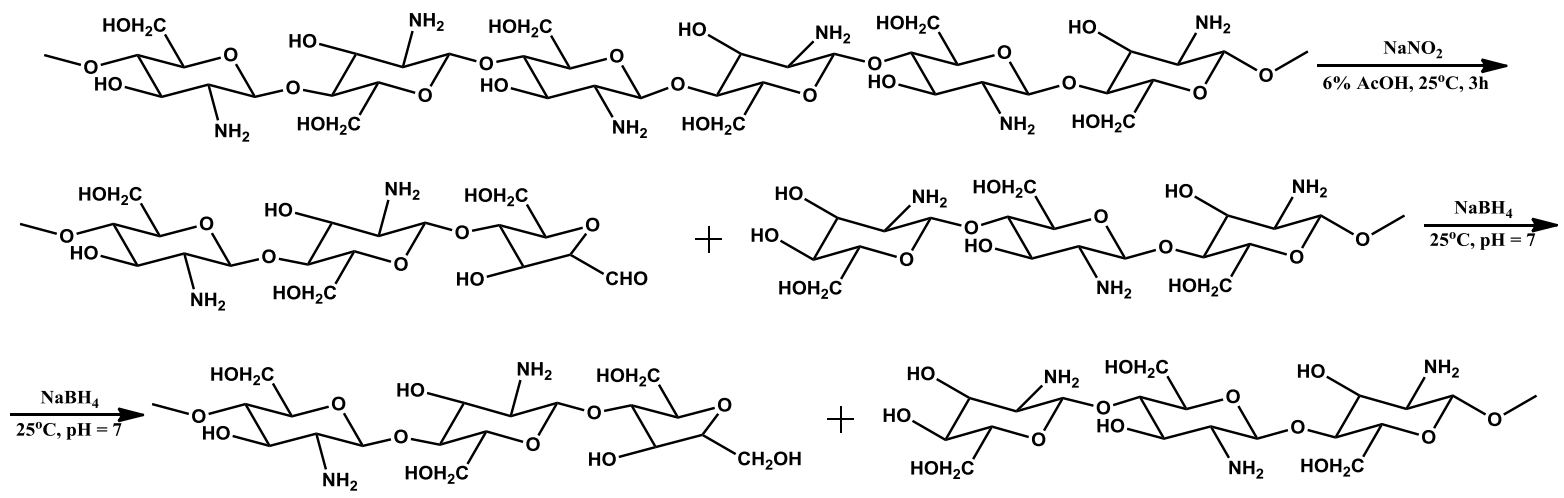

\section{Scheme 1}

After that, the product of depolymerization is introduced in the reaction with chloroacetic acid $\left(20 \% \mathrm{NaOH}\right.$ solution, $\left.\mathrm{t}<6^{\circ} \mathrm{C}\right)$ and glycidyl-trimethylammonium chloride ( $\mathrm{pH}=7,70^{\circ} \mathrm{C}, 10$ hours) (Scheme 2). 


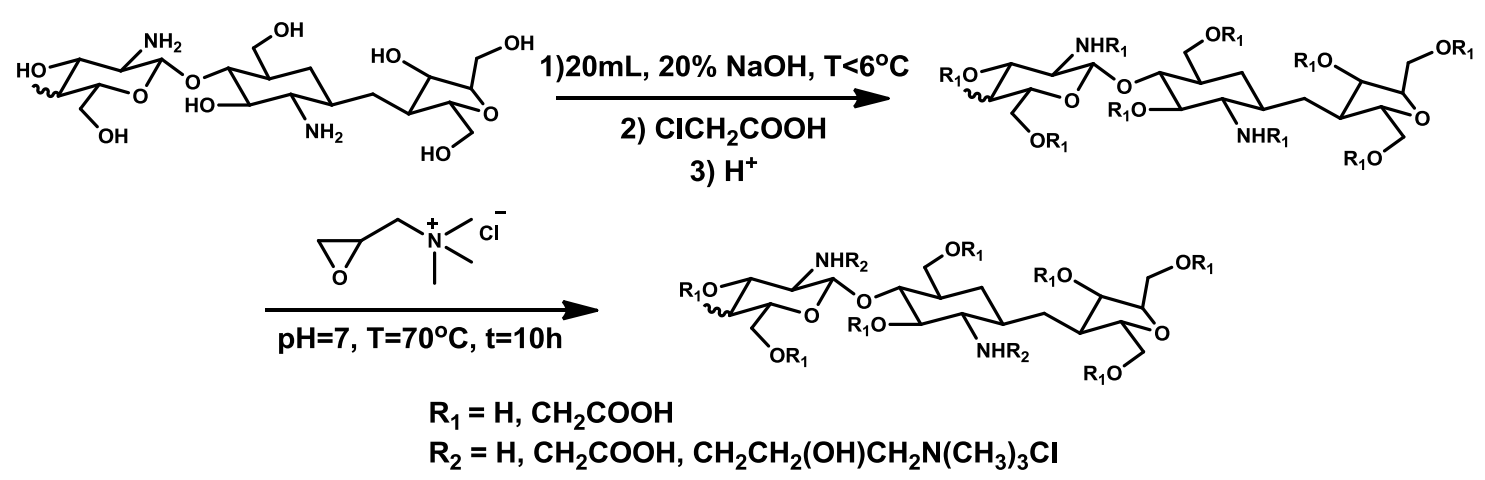

Scheme 2

For this chitosan-based inhibitor, it has been found that the fluorescence maximum is located at $460 \mathrm{~nm}$ and the inhibitor fluorescence intensity is directly proportional to its concentration with a correlation coefficient equal to 0.99 (the detection limit is $0.6046 \mathrm{mg} / 1$ in the concentration range $5-100 \mathrm{mg} / 1$ ), and constant stable level of detection can be provided in a wide $\mathrm{pH}$ range.

\subsubsection{Radical polymerization used to implement fluorophore moiety into polymer structure}

The first approach is used for the radical involved synthesis of co-polymers bearing carboxylate, sulfonic or polyalkylenoxyde groups (acrylic, methacrylic or maleic acids) and the dyes with an active double bond. The synthesis is usually performed in an aqueous solution and is being initiated by persulfates, $\mathrm{H}_{2} \mathrm{O}_{2}$, benzoylperoxide or $2,2^{\prime}$-azobisisobutyronitrile (0.1-1.0\%, mass). Such molecular weight regulators as sulfur compounds [48] or sodium hypophosphite are normally used [49]. This provides the ability to obtain polymers with the molecular masses $\left(\mathrm{M}_{\mathrm{W}}\right)$ within 2000 to $200000 \mathrm{Da}$ range. The low molecular mass $\mathrm{M}_{\mathrm{W}}$ of a polymer $\left(1000 \mathrm{Da}<\mathrm{M}_{\mathrm{W}}<10000 \mathrm{Da}\right)$ is known to provide the most effective scale inhibition.

Generally, the fluorescent markers should meet the following requirements: (i) synthetic availability of fluorescent dyes capable to participate in polymerization reactions; (ii) chemical stability of the dye molecule in polymerization reactions; (iii) minimal influence (no influence) of dye molecules on the polymer structure and its $\mathrm{M}_{\mathrm{W}}$; (iv) the polymer structure should not affect the optical properties of the fluorescent molecule.

Fluorescent monomers used to obtain scale inhibitors, can be divided into three groups depending on the chemical structure:

1) Aromatic hydrocarbons and their derivatives (polyphenyl hydrocarbons, hydrocarbons with condensed aromatic rings, hydrocarbons with aryl ethylene and arylacetylene groups)

2) Compounds containing heterocycles (derivatives of five-membered and six-membered heterocycles)

3) Compounds with a carbonyl group 
Scale inhibitors containing organic fluorophores based on polyaromatic compounds

Polyphenyl hydrocarbons and hydrocarbons with condensed benzene rings reveal an intensive fluorescent response in the violet and blue spectral regions upon photoexcitation. 9-Vinylanthracene [50] (Rhodia Operations, France), 2-allyloxynaphthyl-6,8-potassium disulfonate [51] (China National Offshore Oil Corp.; PRC) and 5-allyldibenzosuberol [52] (Kurita Water Industries Ltd., Japan) represent the fluorophores from this group (Figure 4).<smiles>C=Cc1cc2ccccc2c(C=C)c1C=C</smiles>

9-vinylantracene<smiles>C=CCOc1ccc2cc(S(=O)(=O)O)cc(S(=O)(=O)O[Na])c2c1</smiles>

2-allyloxynaphtyl-6,8potassium disulfonat

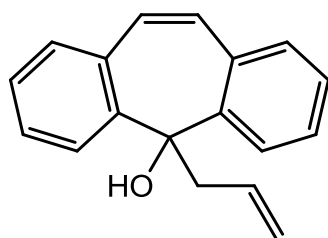

5-allyldibenzosuberenol

Figure 4. Chemical structures of 9-vinyl anthracene, 2-allyldibenzosuberenol and 8-(allyloxy)-1,3,6-pyrene trisulfonic acid.

However, the derivatives of trisodium salt of 8-hydroxypyrene-1,3,6-trisulfonic acid (pyranine), trisodium salt of 8-allyloxypyrene-1,3,6-trisulfonic acid in particular, are the most widely reported as fluorescent monomers in the scientific literature. This fluorescent monomer is used as a co-monomer in the radical copolymerization with various monomers. For example, copolymerization with acrylic acid and allyl polyethoxycarboxylate can be performed (Scheme 3), the resulting polymer demonstrates good results in scale inhibition of carbonate [53] and calcium sulfate [54] deposits.

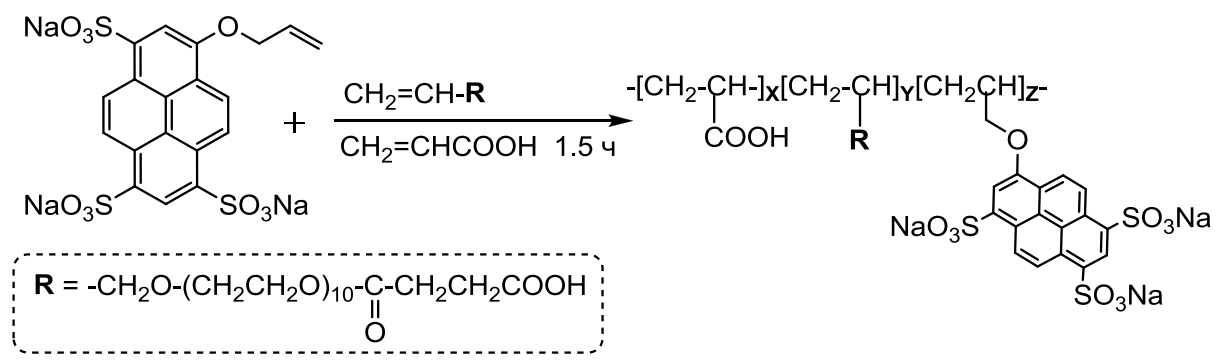

Scheme 3. Scale inhibitors containing organic fluorophores derived from five-membered and six-membered heterocycles.

Despite the fact that the largest group of organic fluorophores includes fivemembered and six-membered heterocycles, the number of papers on these compounds used as fluorescent markers or monomers for modification is not large. In the range of xanthene dyes fluorescent monomers for scale inhibitors based on fluorescein [55] and rhodamine 6G [56] were obtained. 
Patent of Kemira Chemicals Inc. (USA) [57] describes a polymer scale inhibitor with fluorescent marker, which is synthesized from 1-vinylimidazole monomer. Its structure is presented in Scheme 4.

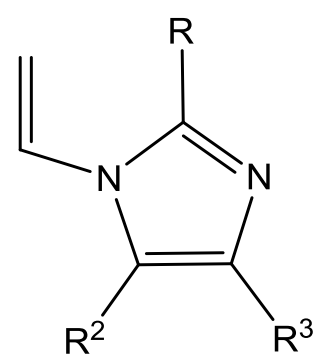

$\mathrm{R}, \mathrm{R}^{2}, \mathrm{R}^{3}=\mathrm{H}, \mathrm{Alk}, \mathrm{Ar}, \mathrm{OPO}_{3} \mathrm{H}, \mathrm{NO}_{2}, \mathrm{OSO}_{3} \mathrm{H}$

Scheme 4

Patent [58] of Nanking University of Science and Technology (PRC) introduces a corrosion and scale inhibitor (Scheme 5) based on a tetrapolymer, which is obtained by copolymerizing benzoimidazole-based fluorescent monomer, maleic anhydride, acrylic acid and 2-acrylamido-2-methyl propane sulfonic acid in aqueous solution at a temperature of $85-95^{\circ} \mathrm{C}$ in the presence of isopropanol and polymerization initiator (ammonium persulfate).

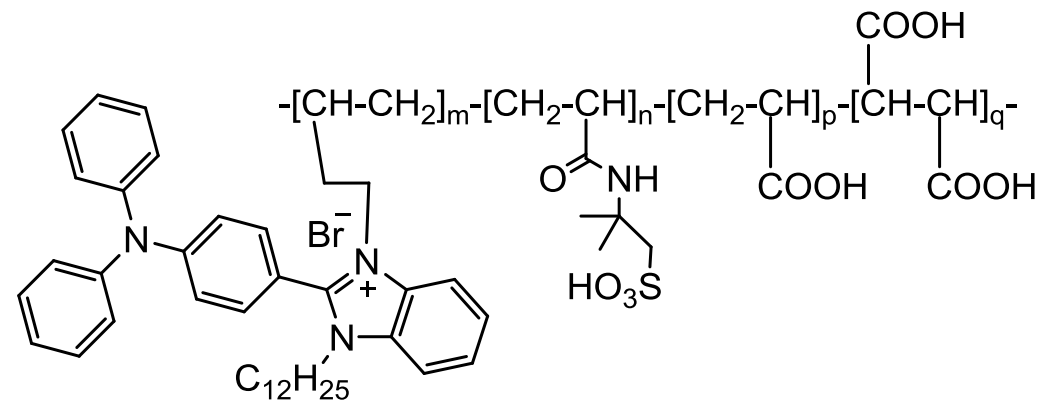

Scheme 5. Scale inhibitors containing organic fluorophores with a carbonyl group.

The same group [57] proposes a polymer inhibitor of corrosion and scaling (Scheme 6), which includes fluorescent fragment of dimethyl-(4-(7-methoxycoumarin))methyl(acroloyloxy)ethyl ammonium bromide, exhibiting fluorescence maximum at $390 \mathrm{~nm}$.

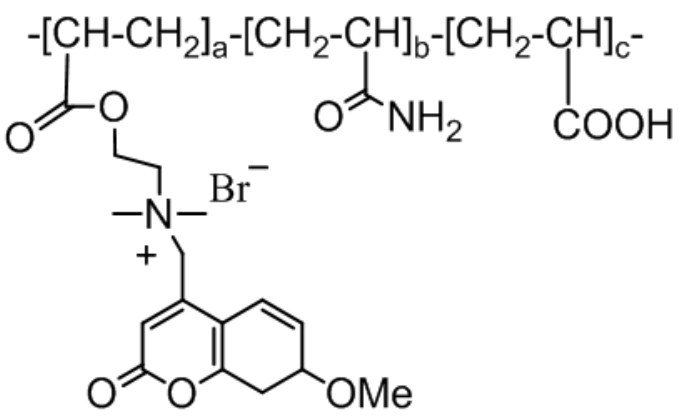

Scheme 6 
A significant number of papers are devoted to the usage of naphthalic acid imide derivatives as fluorescent markers [59-63]. This class of compounds has already found a wide range of practical applications as fluorescent markers in biochemical analysis or sensors $[59,60]$. This is due to both the synthetic availability of 1,8-naphthalimide derivatives [61], including derivatives containing polymerized functional groups [62, 63], and their outstanding optical characteristics (intensive absorption, high fluorescence quantum yields, high photostability, sensitivity of photophysical characteristics to the external media and the chemical nature of the introduced substituents). A noticeable advantage of the optical platform of 1,8-naphthalimide is the possibility of adjusting the optical properties by varying substituents in the 4th position of the naphthalimide nucleus. For example, a replacement of nitrogen atom by an oxygen allows to shift the fluorescence maximum to the blue range of spectrum [64].

Nalco (USA) patent [14] proposes fluorescent monomers (Scheme 7), which are used by the authors to obtain polymer scale inhibitors for water circulation systems by copolymerizing them with acrylic monomer.

a

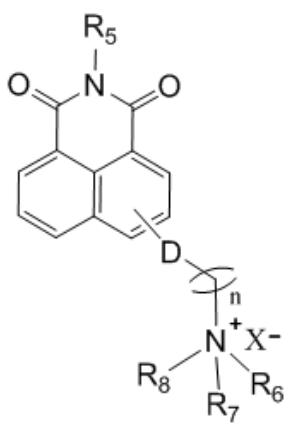

$\mathrm{b}$

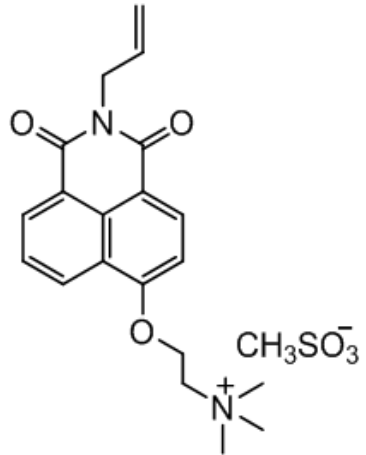

Scheme 7. $n=1-10 ; \mathrm{R} 6, \mathrm{R} 7=$ alkyl; R8 = allyl, alkyl, vinylbenzyl or 2-hydroxy-3allyloxypropyl; R5 = alkyl, alkylamino group, hydroxyalkyl or allyl; D = O or $\mathrm{N}$ or S or absent; $\mathrm{X}=$ anion (counterion).

\subsubsection{Polycondensation as the method of introducing a fluorescent marker in the composition of the polymer}

This approach can be used to obtain polyaspartic acid derivatives. Their preparation is based on polysuccinimide, which can be easily introduced into acylation reactions. Polysuccinimide can be obtained by heating L-aspartic acid in the presence of a catalyst; however, this way of obtaining polymer is expensive, due to the high cost of L-aspartic acid, which is a product of ammonium fumarate biotransformation by Escherichia coli [65]. A different way to produce polysuccinimide is to condense maleic anhydride with ammonia or urea [66-68]. Researches from Zhanjiang Pedagogical University, Zhanjiang, China, proposed to use various derivatives of carbazole as a fluorescent label "embedded" into the polymer inhibitor: 3-amino-9-ethylcarbazole [69], $\mathrm{N}$-(2,3-epoxypropyl)carbazole [70-73]. 
Polysuccinimide, which can be obtained by condensation with urea, reacts with ethanolamine in DMF at room temperature giving the polymer PHPSI (Scheme 8), which is the starting material for subsequent transformations. The polymer containing hydroxyl groups dissolves sufficiently well in DMF when heated, which allows the reaction with $p$-toluenesulfonyl chloride to form the corresponding activated ester, which in turn reacts with 3-amino-9-ethylcarbazole (Scheme 14) to form FPSI. Subsequent alkaline hydrolysis produces a biodegradable fluorescent scale inhibitor FPASP with fluorescence maximum centered at $428 \mathrm{~nm}$. In case of $N$-epoxypropylcarbazole, it is proposed to use direct O-alkylation in the presence of a catalyst $\left(\mathrm{BF}_{3}\right.$ complex with diethyl ether) $[70,71,73]$. It was found that the dependence of the fluorescence intensity on the inhibitor concentration is linear in the range of $1-9 \mathrm{mg} / 1$. The detection limit of the inhibitor is $0.50 \mathrm{mg} / 1$.

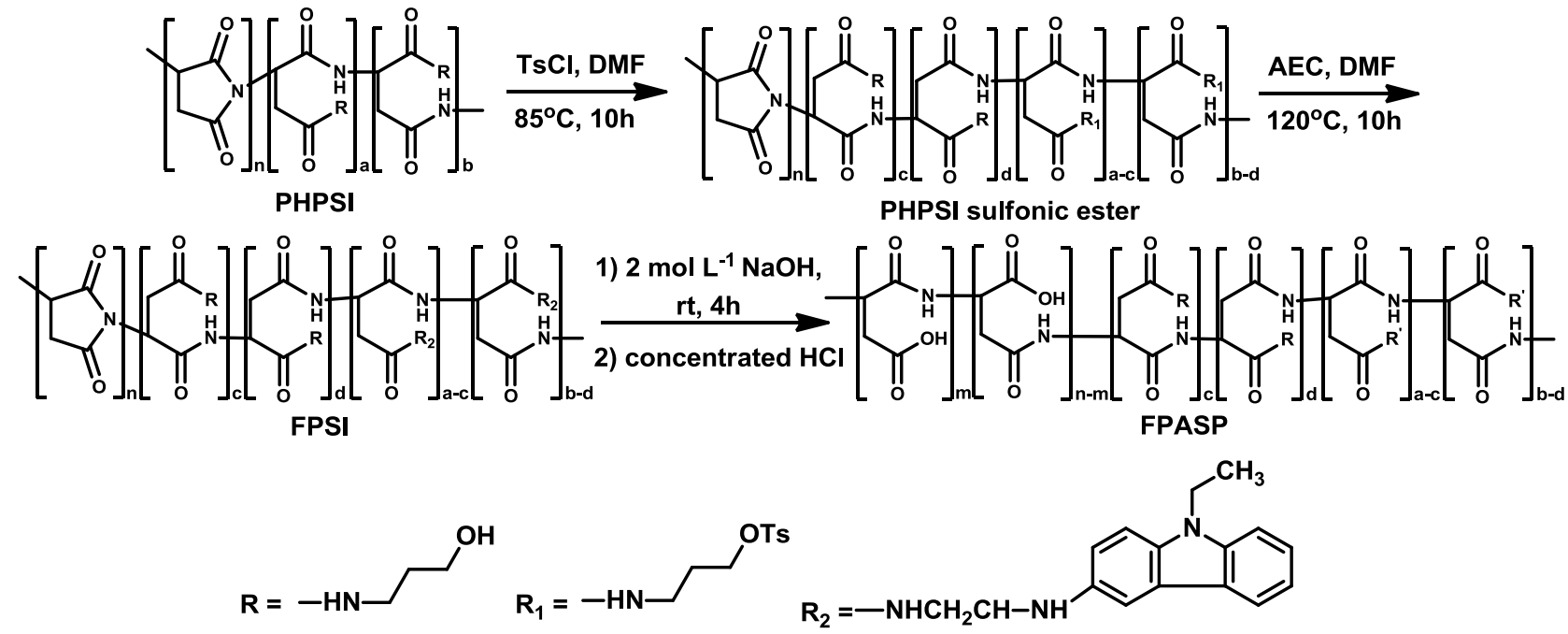

Scheme 8. PHPSI = product of polysuccinimide reaction with ethanolamine $\mathrm{HO}-\mathrm{CH}_{2} \mathrm{CH}_{2}-\mathrm{NH}_{2}$; $\mathrm{TsCl}=p$-toluenesulfonyl chloride; $\mathrm{DMF}=N, N$-dimethylformamide; $\mathrm{AEC}=3$-amino-9ethylcarbazole.

\subsection{Fluorescent-tagged phosphonates}

Currently, phosphates, polyphosphates and salts of phosphonic acid have become highly recommended as phosphorus-containing scale inhibitors (Figure 1) [43,74]. Despite the fact that nowadays these scale inhibitors are widely used in water treatment technologies, there are no examples of real-time monitoring of their content by means of fluorescence spectroscopy. At the same time, there is a great variety of examples described in the scientific periodicals of phosphorous-containing fluorescent molecular sensors for anions, in particular phosphate and pyrophosphate anion sensors are well investigated [60].

Most of publications refer to biochemical analysis [75] because of a high demand for a selective determination of pyrophosphate anion content, which is a residue of an ATP hydrolysis. Thus such an analysis provides ATP hydrolysis monitoring and control [76]. A widely known disadvantage of inorganic polyphosphates is their relatively high hydrolysis rate, or conversion to phosphates, which worsens the scale inhibition and 
creates additional problems associated with the formation of calcium orthophosphate [43]. A replacement of oxygen atom bound to two phosphonate molecules $(\mathrm{P}-\mathrm{O}-\mathrm{P})$ by a carbon atom $(\mathrm{P}-\mathrm{C}-\mathrm{P})$ significantly increases the stability of organophosphonates (HEDP) to hydrolysis.

Recently, there has been stated a tendency to conjugate bisphosphonates with other molecules in order to obtain compounds with new perspective properties. For example, conjugation of a bisphosphonate with a fluorescent dye allows to create both contrast agents for screening microcalcinoses for breast cancer [77, 78], and biologically active derivatives that allow monitoring of the treatment process by the fluorescent response. Examples of such bifunctional compounds are presented in the literature [8,79]. These compounds are proposed by the authors as effective contrast agents for fluorescent imaging. However, these molecules have a very complex chemical structure, which significantly limits their practical applications (Figure 5).

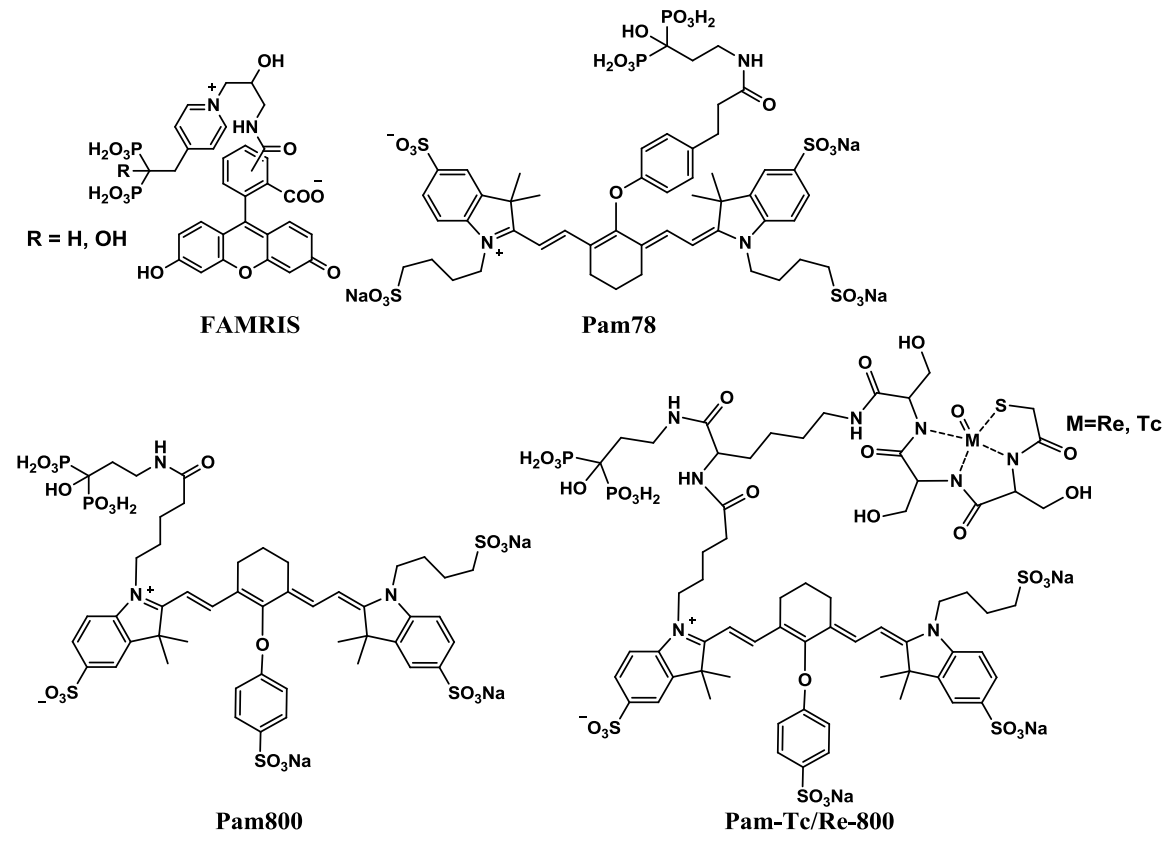

Figure 5. Structures of some fluorescent bisphosphonates.

However, there is only a single report on the synthesis of a fluorescent-tagged phosphonate-based antiscalant: 1-hydroxy-7-(6-methoxy-1,3-dioxo-1H-benzo[de]isoquinolin-2(3H)-yl)heptane-1,1-diyldi(phosphonic acid), HEDP-F [37], Figure 6. HEDP-F is a closest analogue of a well known scale inhibitor, 1-hydroxyethane-1,1-bisphosphonic acid (HEDP, $\mathrm{H}_{4}$ hedp). 


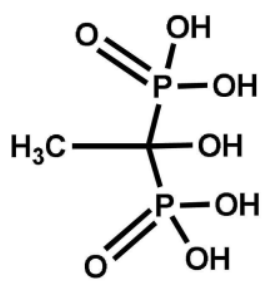

HEDP

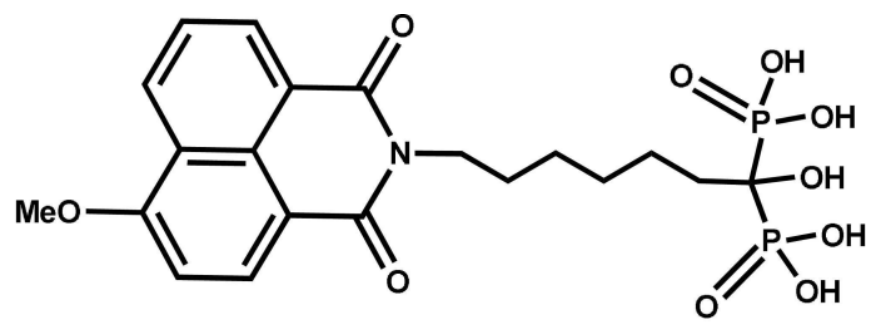

HEDP-F

Figure 6. HEDP and HEDP-F molecular structures

The synthesis of HEDP-F was performed according to the scheme 9, having (7-(6methoxy-1,3-dioxo-1H-benzo[de]isoquinolin-2(3H)-yl)heptanoic acid) 1 as a starting material [37].

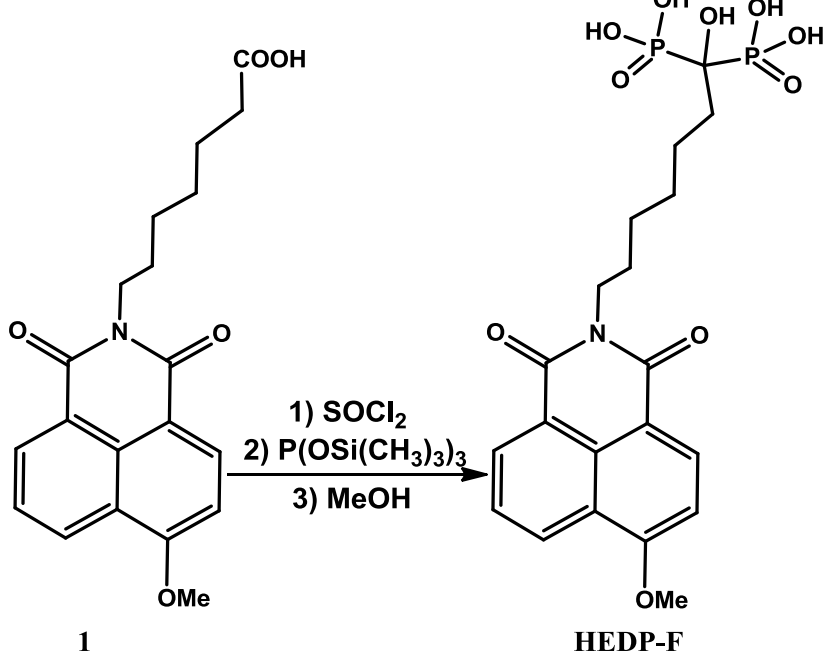

Scheme 9

\section{Fluorescent and antiscalant properties of fluorescent-tagged scale inhibitors}

An antiscaling ability of fluorophore-tagged polymers relative to their non-tagged analogues was reported in a very few studies [15,21,81,82], Table 1, while for luminescent phosphonates only a single publication is registered [37], Table 2. Normally the implementation of a fluorophore fragment either does not change the inhibitor efficacy, or even provides some enhancement.

Nevertheless, more volume of further research and experimental work in this field is in high demand to clarify the situation.

Fluorescent-tagged antiscalants [21,37] reveal fluorescent properties very similar to those demonstrated by corresponding individual dyes (fluorescein, 1,3,6,8-pyrene tetrasulfonic acid tetrasodium salt) [84, 85], Table 3. 
Table 1. The antiscaling ability of fluorophore-tagged polymers relative to their non-tagged analogues.

\begin{tabular}{|c|c|c|c|}
\hline $\begin{array}{c}\text { Fluorescent-tagged scale } \\
\text { inhibitors } *\end{array}$ & $\begin{array}{l}\text { Concentration scale } \\
\text { inhibitors, } \mathrm{mg} \cdot \mathrm{dm}^{-3}\end{array}$ & Inhibitor efficacy, \% & Ref. \\
\hline \multicolumn{4}{|c|}{$\mathrm{CaCO}_{3}$ scale } \\
\hline PA-F1 & 10 & $49 \pm 3$ & [21] \\
\hline PA-F2 & 10 & $51 \pm 2$ & [21] \\
\hline MA-AA-F1 & 10 & $44 \pm 2$ & [21] \\
\hline MA-AA-F2 & 10 & $54 \pm 2$ & [21] \\
\hline PA & 10 & $70 \pm 2$ & {$[21]$} \\
\hline FPASP & 6 & 90 & {$[15]$} \\
\hline PASP & 6 & 70 & [15] \\
\hline \multicolumn{4}{|c|}{$\mathrm{CaSO}_{4}$ scale } \\
\hline PA-F1 & 10 & $73 \pm 3$ & {$[21]$} \\
\hline PA-F2 & 10 & $78 \pm 2$ & {$[21]$} \\
\hline MA-AA-F1 & 10 & $61 \pm 2$ & [21] \\
\hline MA-AA-F2 & 10 & $65 \pm 2$ & [21] \\
\hline PA & 10 & $58 \pm 2$ & {$[21]$} \\
\hline AA-APEM-APTA & 9 & 96 & {$[81]$} \\
\hline AA-APEM & 9 & 95 & {$[81]$} \\
\hline PAA & 9 & 85 & [81] \\
\hline \multicolumn{4}{|c|}{$\mathrm{Ca}_{3}\left(\mathrm{PO}_{4}\right)_{2}$ scale } \\
\hline FPASP & 12 & 95 & {$[82]$} \\
\hline PASP & 12 & 30 & [82] \\
\hline
\end{tabular}

PA-F1 - copolymer acrylic acid- N-allyl-4-methoxy-1,8-naphtalimide

PA-F2 - copolymer acrylic acid-N-allyl-2-(6-hydroxy-3-oxo-3H-xanthen-9-yl)benzamide

$(\mathrm{N}$-allylamidefluorescein)

MA-AA-F1 - copolymer acrylic acid - fumaric acids-N-allyl-4-methoxy-1,8-naphtalimide

MA-AA-F2 - copolymer acrylic acid - fumaric acids-N-allyl-2-(6-hydroxy-3-oxo-3 $H$-xanthen-9-yl)benzamide

(N-allylamidefluorescein)

PA - Na-salt of polyacrylic acid (Shandong TaiHe Water Treatment Co. Ltd.)

FPASP - fluorescent polyaspartic acid was synthesized with partially ethanolamine-modified polysuccinimide, $p$-toluenesulfonyl chloride and 3-amino-9-ethyl carbazole.

AA-APEM-APTA - copolymer acrylic acid-oxalic acid-allylpolyethoxy carboxylate-8-hydroxy-1,3,6-pyrene trisulfonic acid trisodium salt (pyranine)

AA-APEM - copolymer acrylic acid - oxalic acid - allylpolyethoxy carboxylate

PAA - poly(acrylic acid) $1800 \mathrm{MW}$ 
Table 2. HEDP-F and HEDP Gypsum Scale Inhibition Efficiency Evaluation by NACE Protocol

\begin{tabular}{ccccc}
\hline \multirow{2}{*}{ Inhibitor } & \multicolumn{2}{c}{ Dosage } & Gypsum scale inhibition, $\%$ & Ref. \\
\cline { 2 - 3 } & $\mathbf{m m o l} \cdot \mathbf{d m}^{-\mathbf{3}}$ & $\mathbf{m g} \cdot \mathbf{d m}^{\mathbf{3}}$ & & \\
\hline HEDP-F & 0.050 & 25 & $78 \pm 9$ & {$[37]$} \\
\hline HEDP & 0.050 & 10 & $92 \pm 4$ & {$[37]$} \\
\hline HEDP & 0.016 & 3 & 53 & {$[83]$} \\
\hline
\end{tabular}

Table 3. Fluorescence efficiency of the inhibitors

\begin{tabular}{ccccc}
\hline Inhibitor / dye & $\lambda^{\text {abs }}, \mathbf{n m}$ & $\boldsymbol{\lambda}^{\mathbf{f}}, \mathbf{n m}$ & $\mathbf{\Phi}^{\mathbf{f}}$ & Ref. \\
\hline fluorescein & $\begin{array}{c}473(\text { Buffer } \mathrm{pH} 5.0) ; \\
490(\text { Buffer } \mathrm{pH} 9.0)\end{array}$ & $\begin{array}{c}514 \text { (Buffers } \\
\mathrm{pH} \mathrm{5.0,} \mathrm{pH} 9.0)\end{array}$ & 0.92 & {$[84]$} \\
\hline $\begin{array}{c}\text { 1,3,6,8-pyrene tetrasulfonic } \\
\text { acid tetrasodium salt }\end{array}$ & 374 & 403 & 56 & {$[85]$} \\
\hline PA-F1 & 375 & 465 & 0.69 & {$[21]$} \\
\hline PA-F2 & 476 & 515 & 0.88 & {$[21]$} \\
\hline MA-AA-F1 & 375 & 465 & 0.69 & {$[21]$} \\
\hline MA-AA-F2 & 476 & 515 & 0.86 & {$[21]$} \\
\hline HEDP-F & 375 & 460 & 0.86 & {$[37]$} \\
\hline$\lambda^{\text {abs }}$ and $\lambda^{\mathrm{f}}$ wavelengths that corresponds to the maximal light absorption and maximal fluorescence \\
respectively; $\Phi^{\mathrm{f}}$ denotes the fluorescence quantum yield; see Table 1 for the antiscalant abbreviations. \\
\hline
\end{tabular}

Only a single paper reports on the influence of the background cations content on the quantum yield of an antiscalant [21], Table 4. The corresponding data clearly indicate, that cations can either increase or sufficiently diminish the fluorescence intensity of some Fluorescent-tagged polymers, while some other stay insensitive to this influence. Anyhow this property has to be taken into account for any particular application of a tracer.

The analytical method of fluorimetric determination of a scale inhibitor content in water involves irradiation of a sample of water containing a polymer with a fluorescent label with UV light wavelength $\lambda^{\text {abs }}$, and monitoring the fluorescence intensity of a solution at $\lambda^{\mathrm{f}}$. As shown in Figures 7 and 8, a directly proportional dependence of the fluorescence intensity on the mass concentration of the reagent PAA-F2 is observed at a wavelength of $\lambda=515 \mathrm{~nm}$. According to the data, we obtained calibration curve (Figure 4), which proved to be linear within this concentration region. 
Table 4. The dependence of $10 \mathrm{mg} \cdot \mathrm{dm}^{-3}$ inhibitor fluorescence intensity on inorganic cation concentration $\left(\mathrm{pH} 8.0,25^{\circ} \mathrm{C}\right)[21]$.

\section{Cation}

\begin{tabular}{cccccccccc}
\hline \multicolumn{1}{c}{$\mathrm{Ca}^{2+}$} & $\mathrm{Mg}^{2+}$ & \multicolumn{2}{c}{$\mathrm{Zn}^{2+}$} & \multicolumn{2}{c}{$\mathrm{Cu}^{2+}$} & \multicolumn{2}{c}{$\mathrm{Fe}^{3+}$} \\
\hline \multicolumn{8}{c}{ Cation concentration, $\mathbf{m g} \cdot \mathbf{d m}^{-3}$} \\
\hline 20 & 200 & 10 & 100 & 2 & 20 & 0.5 & 5 & 0.3 & 3 \\
\hline
\end{tabular}

Fluorescence intensity change (FE), \%

\begin{tabular}{ccccccccccc}
\hline PA-F1 & $100 \pm 1$ & $93 \pm 1$ & $100 \pm 1$ & $100 \pm 1$ & $97 \pm 1$ & $96 \pm 1$ & $91 \pm 1$ & $74 \pm 1$ & $99 \pm 1$ & $94 \pm 1$ \\
\hline PA-F2 & $58 \pm 1$ & $43 \pm 1$ & $66 \pm 1$ & $62 \pm 1$ & $85 \pm 1$ & $42 \pm 1$ & $96 \pm 1$ & $48 \pm 1$ & $108 \pm 1$ & $94 \pm 1$ \\
\hline $\begin{array}{c}\text { MA-AA- } \\
\text { F1 }\end{array}$ & $81 \pm 1$ & $71 \pm 1$ & $91 \pm 1$ & $84 \pm 1$ & $93 \pm 1$ & $85 \pm 1$ & $90 \pm 1$ & $74 \pm 1$ & $94 \pm 1$ & $62 \pm 1$ \\
\hline $\begin{array}{c}\text { MA-AA- } \\
\text { F2 }\end{array}$ & $87 \pm 1$ & $81 \pm 1$ & $100 \pm 1$ & $138 \pm 1$ & $93 \pm 1$ & $90 \pm 1$ & $88 \pm 1$ & $69 \pm 1$ & $92 \pm 1$ & $60 \pm 1$ \\
\hline
\end{tabular}

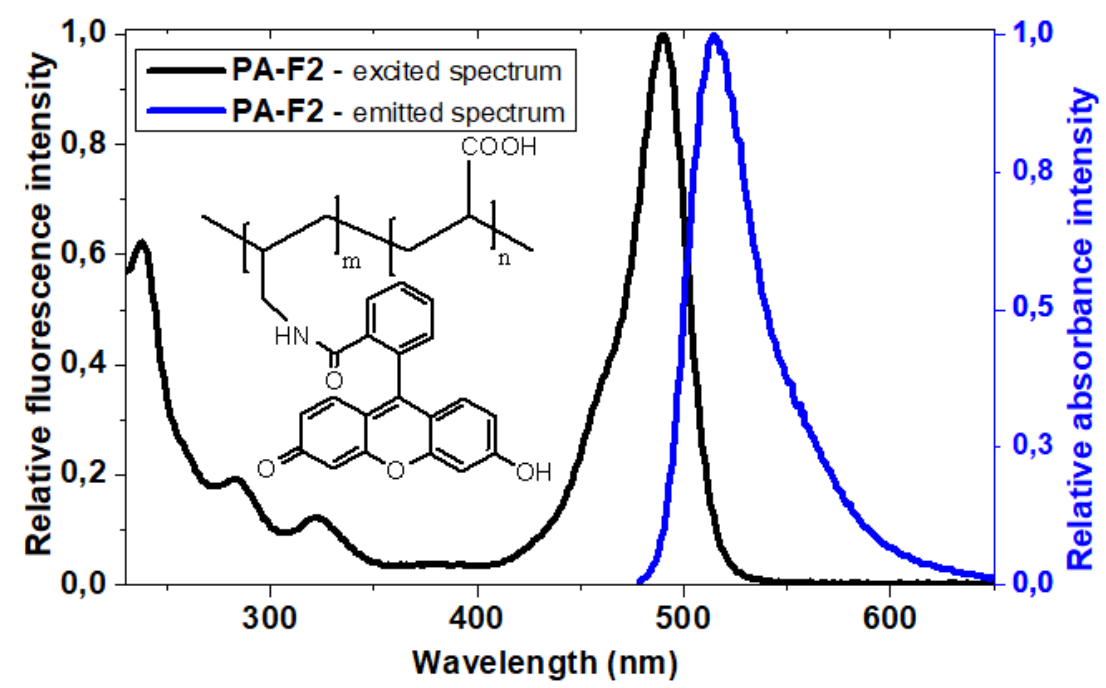

Figure 7. Typical fluorescence and emission spectra of the reagent PA-F2 (a modification of a figure presented in [21]). 


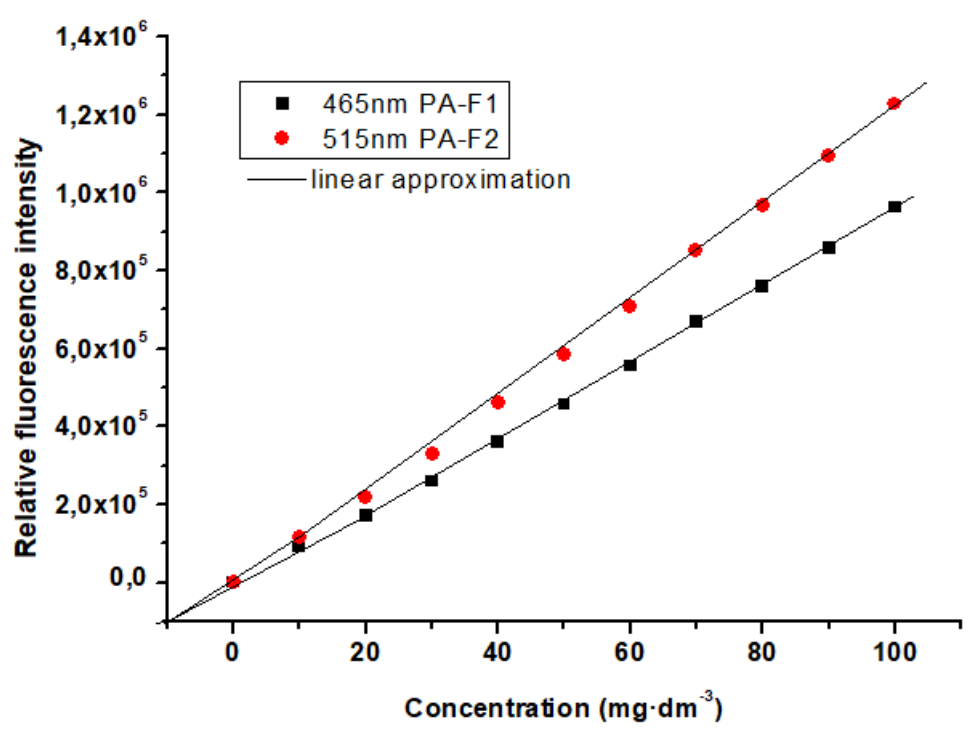

Figure 8. The dependence of the fluorescence intensity of the solution on the mass concentration of the reagents PA-F1, $R^{2}=0.9988$ and PA-F2, $R^{2}=0.9991$, partly reported in [21].

Obvious advantage of this approach is the absence of sample preparation and the ability to reduce measurement error due to elimination of sample dilution.

\section{Applications for a scale inhibitor concentration control in industry}

Industrial application of fluorescent scale inhibitor control is currently represented by just a few examples. Most of them are provided by NALCO Company - the leading company which performs systematic and extensive research, performs design and introduces into practice new systems for automated control by means of fluorescence [4-7, 86-88]. The limitations may be explained by the fact that the fluorescent control requires an installation of additional control equipment, which requires extra funding and/or upgrade of existing companies Technology Park. Nevertheless, the advantages of fluorescent control are quite obvious and the growth of the number of industrial applications of fluorescent scale inhibitor control is expected in the nearest future.

The major industrial applications refer to NALCO TRASAR ${ }^{\circledR}$ technology used for automated feed control cooling systems and reverse osmosis systems [89, 90]. Till now Nalco has been using $\operatorname{Trasar}^{\circledR}$ technology for approximately 30 years. Trasar ${ }^{\circledR}$ operates a $^{\circ}$ chemically "inert" molecule that is highly fluorescent. This compound is blended at a carefully controlled concentration in select Nalco products. When the product is dosed into a water system, a fluorometer is used to measure the fluorescence of the recirculating water. The fluorescence measurement is used to determine treatment dosage and assess need for altering the chemical dosage. Automation can be achieved when a fluorometer is used in-line, continuously or continually sampling and measuring fluorescence. The Trasar controller sends a signal to the product feed pump, keeping it in the on or off position, to maintain control of fluorescent component concentration (indirectly maintaining product 
dosage, Figure 9). When properly performed, fluorescence technology can eliminate the problem of incorrect product feed.

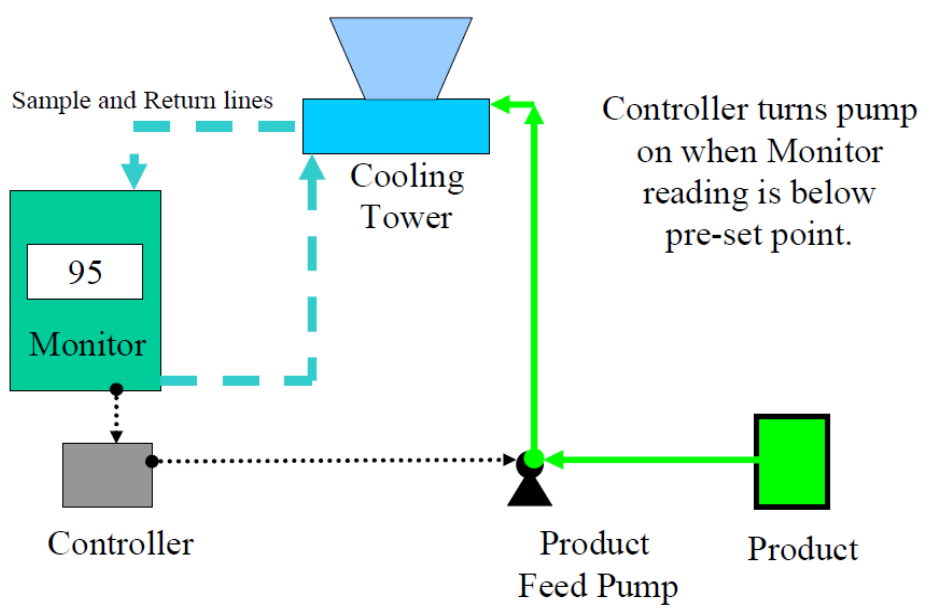

Figure 9. Trasar set-up.

Though Trasar ${ }^{\circledR}$ technology provides a lot of advantages, there are some limitations. The tracer is only an indirect measurement of treatment actives. Consequently, the treatment actives can be misrepresented since the tracer is not consumed and does not typically become part of any deposit. Therefore, chemical analysis for the active constituents (phosphate, polymer, etc.) may still be required. The fluorescent molecule can be expensive, although the high raw material cost is offset somewhat due to small percentage required in the product formulation. The difficulty is in quality control, since the amount of tracer must be very accurate and precise. Variations in the raw material activity or variations in batch size must be measured and corrected for. This can be a laborintensive production process.

In order to overcome the limitations mentioned above Nalco introduced a dispersant polymer that contains a fluorescent "tag". The tagged polymer is claimed to have equal effectiveness as a dispersant compared to the standard, untagged polymer. The tagged polymer's fluorescence can be measured at the same time as the background Trasar molecule in the formulated product. The difference between the background Trasar molecule and the tagged polymer indicates consumption. Consumption of tagged polymer can be directly related to scale formation in the system. It is reportedly more sensitive than DATS $^{\mathrm{TM}}$ units (Deposit Accumulation Testing System provided by Bridger Scientific Inc.) or chemical analyses. Trasar is claimed to negate the need to depend on scale and corrosion indices that are typically used to develop treatment operating guidelines such as system cycles and $\mathrm{pH}$. Besides, it is claimed that it is not necessary to fully understand how much of a particular treatment is required under the possible myriad of operating conditions. Cycles can be increased automatically until scale begins to form, and then the cycles can be reduced to the point where scale formation is prevented, eliminating scale deposition problems. 
Another option is to feed product to maintain a certain level of polymer actives rather than a certain level of product dosage. If a scale begins to develop, precipitating the polymer, the controller will increase the product feed producing an increase in polymer concentration. This is a simpler control approach, but abandons the "automatic optimization" concept. It is not clear what happens when the Tag/Trasar molecule ratio changes-there should at least be some type of alarm.

Further development of Trasar technology was realized for instance in Trasar ${ }^{\circledR} 20209$ cooling water scale and corrosion inhibitor. Trasar 20209 is a molybdate/organophosphonate-based blend of scale and corrosion inhibitors with Nalco TRASAR $^{\circledR}$ Technology for open recirculating cooling water systems. This product was designed for systems with corrosive water (low hardness and/or low alkalinity). TRASAR 20209 allows to provide protection over a wide range of operating parameters. For low hardness/low alkalinity waters, TRASAR 20209 is applicable for $0-350 \mathrm{ppm}$ calcium and M-alkalinity. TRASAR 20209 is also used for zeolite softened water systems (low hardness/low alkalinity). In these applications, the upper alkalinity limit is $2000 \mathrm{ppm}$. TRASAR 20209 should not be used when galvanized iron is part of the system.

In one of recent patents [90] Nalco Company introduced some new promising fluorescent tracers for the Trasar technology. The fluorescent tracers comprise rhodamine dyes. The invention is directed toward a method for measuring concentration and optionally controlling dosage of at least one treatment chemical into industrial wastewater, the method comprising the following steps: providing the industrial wastewater; dosing the at least one treatment chemical into the industrial wastewater to create a treated industrial wastewater, wherein the at least one treatment chemical is traced with a dye; measuring the fluorescence of the treated industrial wastewater; and optionally adjusting the dosing based on the measuring. The invention is also directed toward a method for measuring concentration and optionally controlling dosage of at least one treatment chemical into industrial wastewater, the method comprising the following steps: providing the industrial wastewater; dosing the at least one treatment chemical into the industrial wastewater to create a treated industrial wastewater, wherein the at least one treatment chemical is traced with a dye; measuring the fluorescence of the treated industrial wastewater; and optionally adjusting the dosing based on the measuring; wherein the dye is selected from the group consisting of Rhodamine WT, Sulforhodamine B, Rhodamine B, and combinations thereof.

Besides the cooling water monitoring Nalco Company provides also reverse osmosis applications of fluorescence. Innovations here include 3D TRASAR ${ }^{\circledR}$ Technology for Membranes Platform and TRASAR ${ }^{\circledR}$ RO Control System. 3D TRASAR Technology for Membranes Platform is a flexible control platform designed to provide advanced control of antiscalant treatment programs and enable operational data collection for performance analysis. The system uses an updated version of the 3D TRASAR controller coupled with Nalco fluorescence technology to optimize control of antiscalant programs and enhance monitoring of $\mathrm{pH}$ adjustment and oxidant destruction programs. The expanded capabilities of this new 3D TRASAR controller permit continuous measurement of the key Reverse 
Osmosis system parameters. The data, along with operating data from the customer's DCS can be wirelessly transmitted back to Nalco for analysis, trending, and interpretation. This Web capability provides easy access to data, system reporting, and enables alerting of key personnel to conditions outside of "best practices".

3D TRASAR Technology for Membranes Platform can be customized to handle a variety of reverse osmosis system configurations and upgraded as changes are made to operating conditions or process equipment. The 3D TRASAR for Membranes Platform consists of a number of sensor modules, signal input modules, the Nalco 3D TRASAR controller, and the Nalco Global (wireless) Gateway mounted on a stainless steel frame. TRASAR RO Control System uses a TRASAR controller coupled with Nalco fluorescence technology. The fluorometer continuously measures the exact concentration of traced antiscalant product in the feedwater. The system's integral PID controller uses this signal to precisely control product addition. So, treatment levels are maintained and system can be protected from scale and fouling (Figure 10).

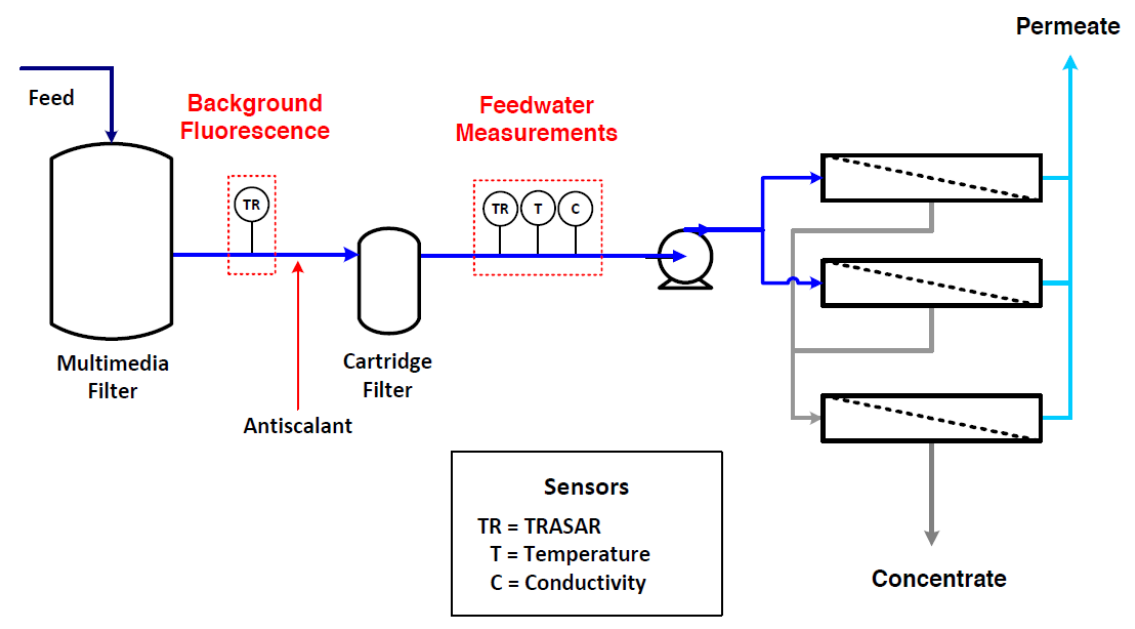

Figure 10. Trasar reverse osmosis system.

TRASAR RO Control System is designed for easy field installation. Installation consists of mounting the controller, plumbing the sample line and drain line, configuring the controller with system parameters, supplying electrical service and wiring the 4-20 mA control output signal to the chemical metering pump. The user-friendly controller interface and handy access to sensors make the system easy to operate. Its compact, field-proven design including a fouling-resistant quartz flow cell minimizes maintenance. TRASAR RO Control Systems provides the sensors, controller and communications interface needed to automate antiscalant treatment programs. It is designed as a frame-mount unit. The system back panel can be removed and mounted on the wall if floor space is limited. A field-mountable background fluorescence kit can be ordered if the water supply has elevated and varying levels of naturally fluorescing compounds. 
An important example of bench-scale and industrial scale evaluation of the antiscaling and fluorescent activity of a novel 1,8-naphthalimide tagged polyacrylate PAA-F1 has been published by our research group recently [91]. The ability of fluorescent 1,8-napthalimide-tagged polyacrylate PAA-F1 to serve as an "on line" indicator of polymeric scale inhibitor concentration has been tested in dynamic bench scale tests operating with EMEC facility, and in an industrial-scale in situ experiment run at a "Rosinka 10/20" cooling tower that provides the circulating water cooling of heat exchangers at rectification columns of ECOS-1 Co. site in Staraya Kupavna city, Russia, with a total cooling water volume of $4.5 \mathrm{~m}^{3}$, Figure 11 . It has been demonstrated that the static beaker tests and the dynamic bench- and industrial-scale experiments may reveal rather different results. The latter exhibited a much higher sensitivity to the background iron cation concentration. It has been found that PAA-F1 may lose up to $17 \%$ of fluorescence intensity, while the losses of indifferent tracer, tetrasodium salt of 1,3,6,8-pyrenetetrasulfonic acid (PTSA) can exceed 80\%. The bench-scale dynamic experiments on the fluorescence intensity of a fluorescent-tagged scale inhibitor at elevated concentrations of the background cations are recommended as an inevitable step for a proper estimation of fluorescent tracer validity for in situ applications. An industrial-scale 30-day experiment has demonstrated a good agreement of the fluorescent data with the conventional methods of cooling water control, and the feasibility of 1,8-naphthalimide tagged polyacrylate PAA-F1 application for in situ polymer concentration monitoring "on line".

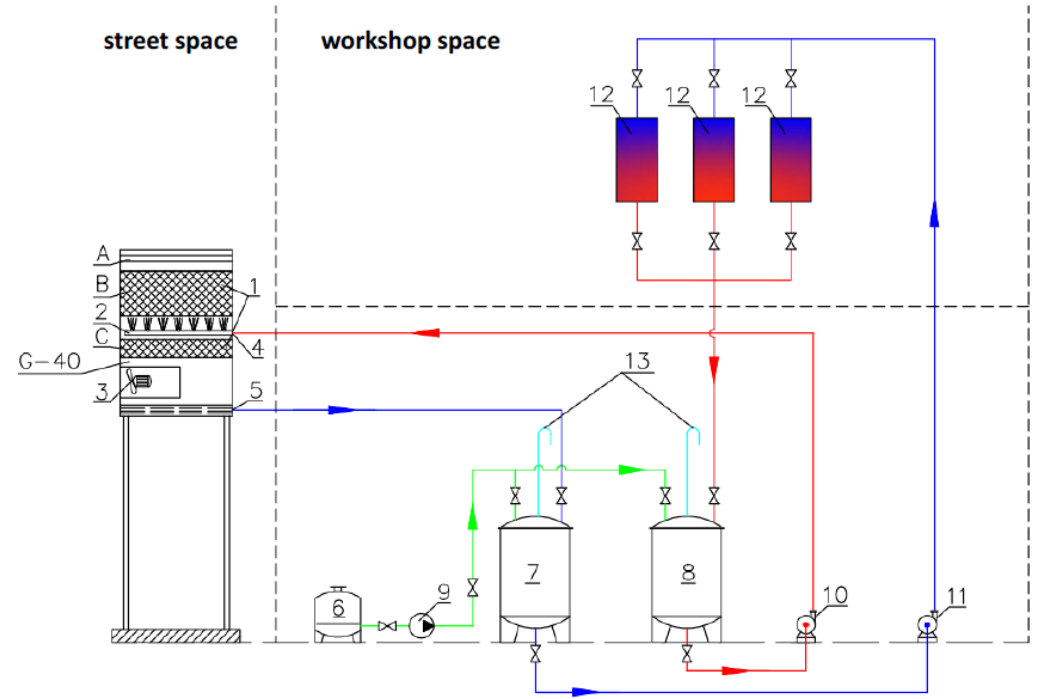

Figure 11. An industrial cooling tower scheme with a rectification column at ECOS-1 Co. site in Staraya Kupavna city. The hot water from the heat exchangers 12 of the rectification columns goes to the collector of heated water 8 . Then it is transferred to the cooling tower G-40 ("Rosinka 10/20") by pump 10. The cooled water is collected in vessel 7, then returned to the heat exchangers (12). The injection of reagents is performed at collectors 7 and 8 from vessel 6 via dosing pump 9. 


\section{Applications in water treatment R\&D}

Besides the issues of antiscalant concentration monitoring in industrial facilities, the fluorescent-tagged scale inhibitors provide a unique opportunity of the scale inhibition theory development via the direct visualization of inhibitor in various scale formation processes. Already the first communication on a task-specific fluorescent-tagged bisphosphonate location during gypsum crystals formation in a supersaturated aqueous solution [37] revealed a mechanism, significantly different from the conventional ones [92-95]. For the bulk heterogeneous crystallization from the supersaturated aqueous solutions in presence of tiny solid impurities it is widely accepted [92-95], that the gypsum nucleation is the initial stage. Gypsum components (calcium and sulfate ions) get adsorbed onto the surface of solid impurities and form the calcium sulfate core there. Then the phosphonate molecules get adsorbed onto gypsum nuclei, thus blocking the gypsum active crystal growth sites. This in turn leads to the gypsum crystal growth retardation and crystal distortion.

However, the visualization of HEDP-F in gypsum supersaturated aqueous solution [37] indicated quite a different mechanism, Figure 12. When calcium and sulfate brines get mixed in presence of an HEDP-F, then phosphonate, $\mathrm{Ca}^{2+}$ and $\mathrm{SO}_{4}^{2-}$ ions compete for the solid particles, initially present in the stock solutions. These particles adsorb in a parallel way either HEDP-F and Calcium, or Calcium and sulfate ions. HEDP-F gets adsorbed onto the surface of solid suspended particles in the form of calcium salts, Figure 12c. Tentatively the phosphonate species "block" the surface of solid suspended particles (gypsum crystallization centers) from calcium and sulfate ions, and do not let $\mathrm{CaSO}_{4} \cdot 2 \mathrm{H}_{2} \mathrm{O}$ crystals to form. Such "blocked" indifferent particles adsorb further HEDP-F sparingly soluble calcium salts. Thus they concentrate almost all fluorescence and are indicated at Figure $12 \mathrm{~b}, \mathrm{c}$ as small spherical green crystals.

Those crystallization centers that absorb initially $\mathrm{Ca}^{2+}$ and $\mathrm{SO}_{4}^{2-}$ ions then proceed to grow, and provide finally the gypsum needle-like macrocrystals Figure 12a,b. Thus the gypsum phase does not indicate any presence of the inhibitor. Those green outgrowths on the gypsum crystals surface that are observed at Figure 12b, are likely to form due to crystals association during their isolation or crystals hetero-aggregation. By no means they indicate the absorbance of inhibitor on the kink sites of $\mathrm{CaSO}_{4} \cdot 2 \mathrm{H}_{2} \mathrm{O}$ crystals as the recent theory predicts [92-95].

Then what makes HEDP-F to act as a gypsum scale formation inhibitor? The tentative solution may be settled on the grounds of a Figure 12b [37]. It can be seen, that the number of green crystals exceeds several times the number of colorless gypsum ones. Therefore the main mechanism of gypsum deposit retardation is associated with a significant decrease of the number of initial gypsum nucleation centers formed on the surface of inert nanoimpurities at the moment when the brines get mixed. Recently we got the confirmation of these results by DLS studies of the same gypsum-phosphonate systems [96,97]. The proposed inhibition mechanism seems to be a universal one, and could be spread out on 
any sparingly soluble salt deposition. Indeed, any aqueous solutions, prepared from analytical grade chemicals, contain some solid particles of unclear origin (the "dust"). The number of such particles can be partly reduced by nanofiltration, but they cannot be eliminated completely.

We have studied also the gypsum crystals, isolated after the NACE protocol treatment in presence of HEDP-F [37], Figure 13. Unlike the scanning electron microscopy, the 3D fluorescence provides a unique possibility to look inside the crystal. Therefore some consequent steps of a crystal formation become visible at once. One can see the bright crystal rod ("lightsaber"), initially formed by nanoparticles, completely covered with HEDP-F. Than this rod becomes a center of gypsum layers, grown without any evident involvement of a HEDP-F antiscalant (massive dark layer). Otherwise these parts of a gypsum crystal should contain the light green spots of an antiscalant, or have to be uniformly colored. At the same time, the anionic forms of HEDP-F that are present in the solution do not seem to affect the gypsum crystals growth. This fact becomes obvious at the third stage. Indeed, after the gypsum crystal formation is finished, the residual HEDP-F molecules get adsorbed onto its surface, particularly at the edges of a crystal lattice, forming the outer layer, Figure 13.

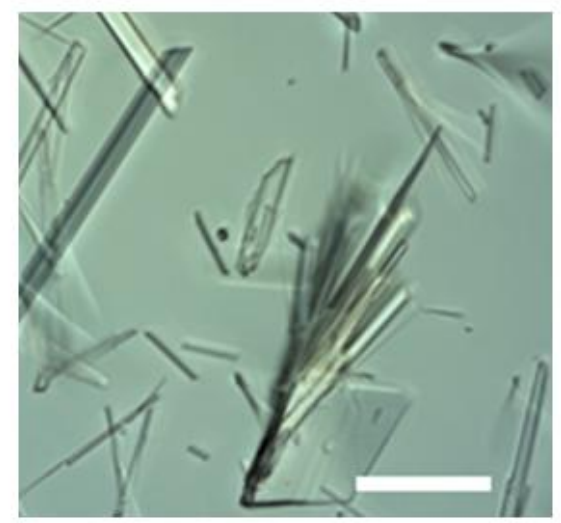

a

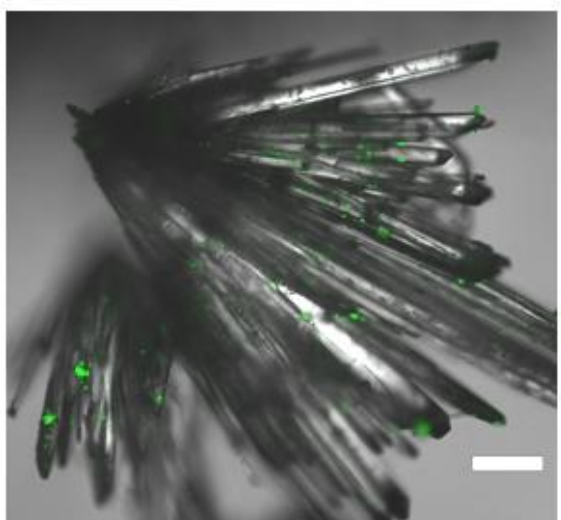

b

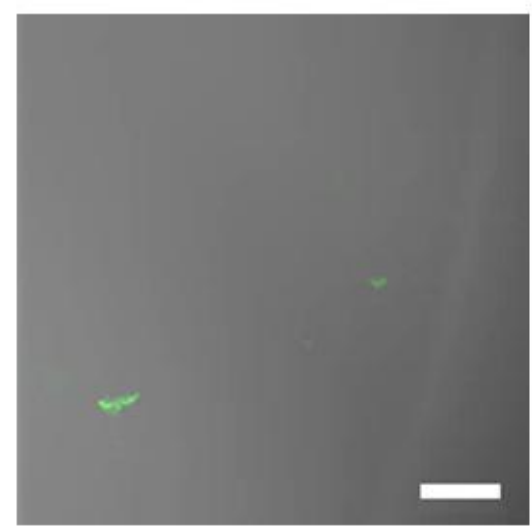

C

Figure 12. Fluorescent images of saturated aqueous solutions: (a) a blank experiment $\left(\left[\mathrm{Ca}^{2+}\right]=\left[\mathrm{SO}_{4}^{2-}\right]=0.075 \mathrm{~mol} \cdot \mathrm{dm}^{-3},[\mathrm{HEDP}-\mathrm{F}]=0 \mathrm{mmol} \cdot \mathrm{dm}^{-3}\right)$; (b) in presence of HEDP-F $\left(\left[\mathrm{Ca}^{2+}\right]=\left[\mathrm{SO}_{4}^{2-}\right]=0.075 \mathrm{~mol} \cdot \mathrm{dm}^{-3},[\mathrm{HEDP}-\mathrm{F}]=0.014 \mathrm{mmol} \cdot \mathrm{dm}^{-3}\right)$; and $(\mathrm{c})$ in absence of sulfate ions $\left(\left[\mathrm{Ca}^{2+}\right]=0.075 \mathrm{~mol} \cdot \mathrm{dm}^{-3},[\mathrm{HEDP}-\mathrm{F}]=0.014 \mathrm{mmol} \cdot \mathrm{dm}^{-3}\right)$. Scale mark corresponds to 100 microns [37]. 


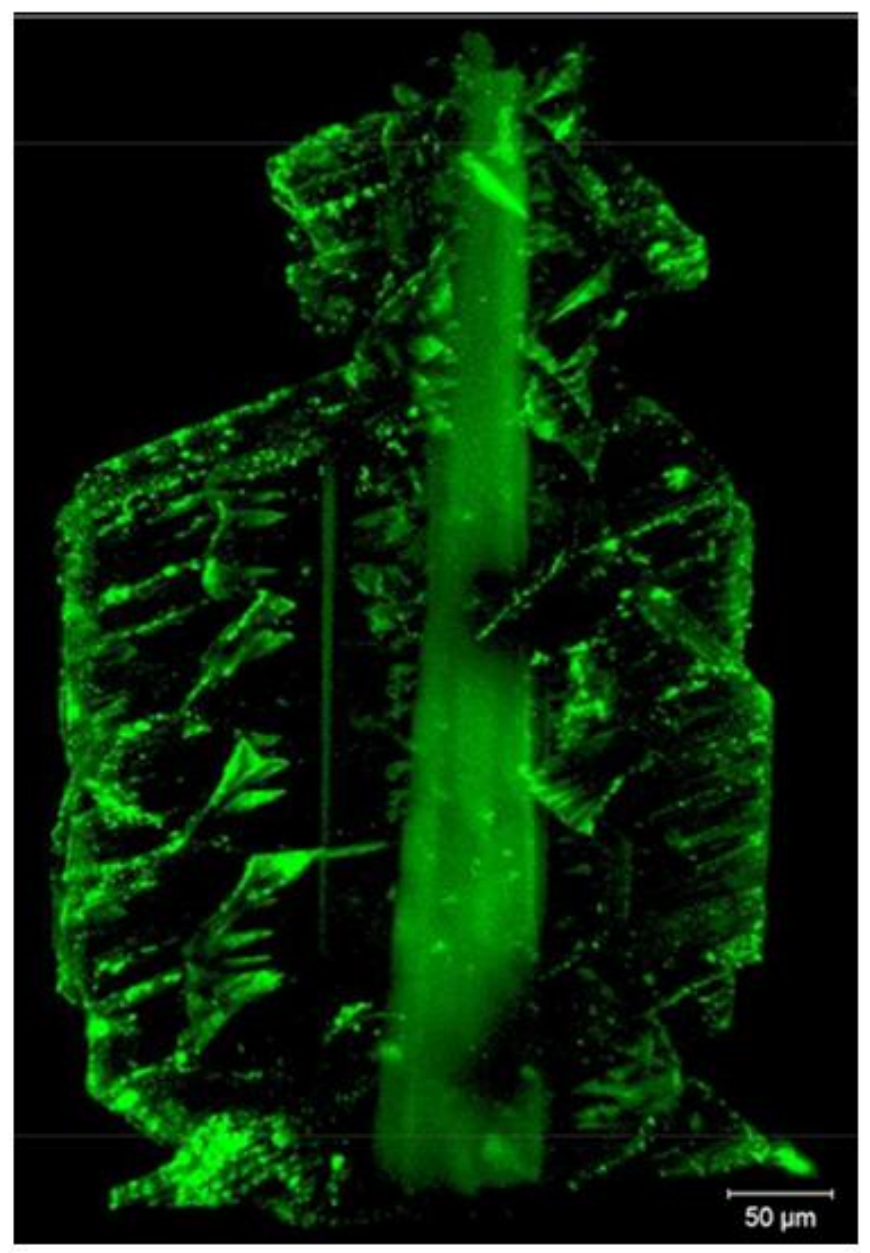

Figure 13. 3D Fluorescent image of gypsum crystal, isolated in presence of $25 \mathrm{mg} \cdot \mathrm{dm}^{-3}$ HEDP-F within the NACE Protocol [37].

Notably, the gypsum formation mechanisms look different at ambient (Figure 12b) and at elevated temperature (Figure 13). However, these results do not conflict each other. Before being mixed both NACE brines also contain a sufficient amount of tiny solid suspended particles (solid impurities). During the incubation period at elevated temperature the gypsum embroys (nuclei) do not form. At the same time, HEDP-F gets adsorbed onto the surface of all solid suspended particles in the form of calcium salts. Thus the differences between the NACE protocol and an ambient temperature experiment are likely due to the different conditions of inert particles coverage by HEDP-F. In the former case almost all of them adsorb antiscalant during 24 hours heating. In the latter case $1 \mathrm{ml}$ of a sulfate brine and $1 \mathrm{ml}$ of water get mixed and equilibrate with HEDP-F solution. Therefore, in this aqueous phase the inert particles get also covered by an antiscalant. Then, the added calcium brine contains the next portion of solid indifferent particles. Thus an excess of phosphonate, $\mathrm{Ca}^{2+}$ and $\mathrm{SO}_{4}^{2-}$ ions compete for such centers, and the nuclei of both Ca-HEDP-F and $\mathrm{CaSO}_{4} \cdot 2 \mathrm{H}_{2} \mathrm{O}$ are spontaneously formed. The nuclei of gypsum then 
grow to the needle-like macrocrystals without an evident presence of HEDP-F on their surface. Meanwhile the nuclei of Ca-HEDP-F arrange the spherical aggregates of much smaller size and demonstrate a perfect fluorescence. In NACE solutions all inert particles have tentatively the core of Ca-HEDP-F. Therefore the gypsum crystals have to form on this crystallization centers upon cooling with some retardation. Thus the "lightsaber" (Figure 13) represents likely the solid suspended particles, completely covered by calcium salts of HEDP-F.

Meanwhile, the differences in gypsum crystals formation indicate the key role of the solid tiny impurities always present in any reagent grade chemicals usually used in all scale inhibition experiments, as well as in the crystal formation studies. Notably, the homogeneous nucleation never exists in a "pure" form, because even the extra pure acids specially manufactured for microelectronics still contain solid suspended particles, to say nothing of reagent grade purity chemicals. Thus the homogeneous nucleation if any always takes place at least along with heterogeneous one. Therefore the differences in gypsum nucleation and crystal growth, indicated in Figures 12 and 13, are completely associated with a degree of solid suspended particles coverage by antiscalant molecules. Anyhow, the visualization of an antiscalant definitely provides an insight into the mechanisms of the scale inhibition.

Our recent preliminary results demonstrate that such an approach may become very fruitful also in the case of antiscalant visualization on the reverse osmosis membranes, Figure 14. Indeed, one can see, that in absence of carbonate scale the polymeric scale inhibitor PA-F1 covers the whole membrane surface uniformly. However, in the case of calcite brine it gets concentrated on the calcium carbonate crystals deposited onto membrane surface.

Actually a lot of work has to be done, operating fluorescent-tagged polyacrylates and phosphonates as a powerful tool of antiscalants mechanisms activity understanding in different water treatment applications.

\section{Conclusions}

The Fluorescent-tagged scale inhibitors appear to become a powerful tool in an "on line" monitoring of polymeric and phosphonate-based antiscalants in water treatment. Besides, their role in an antiscalant traceability within different water treatment technologies (reverse osmosis, oilfield applications, water cooling and heat supply systems, etc.) might become a key one for the further scale inhibition theory development. 

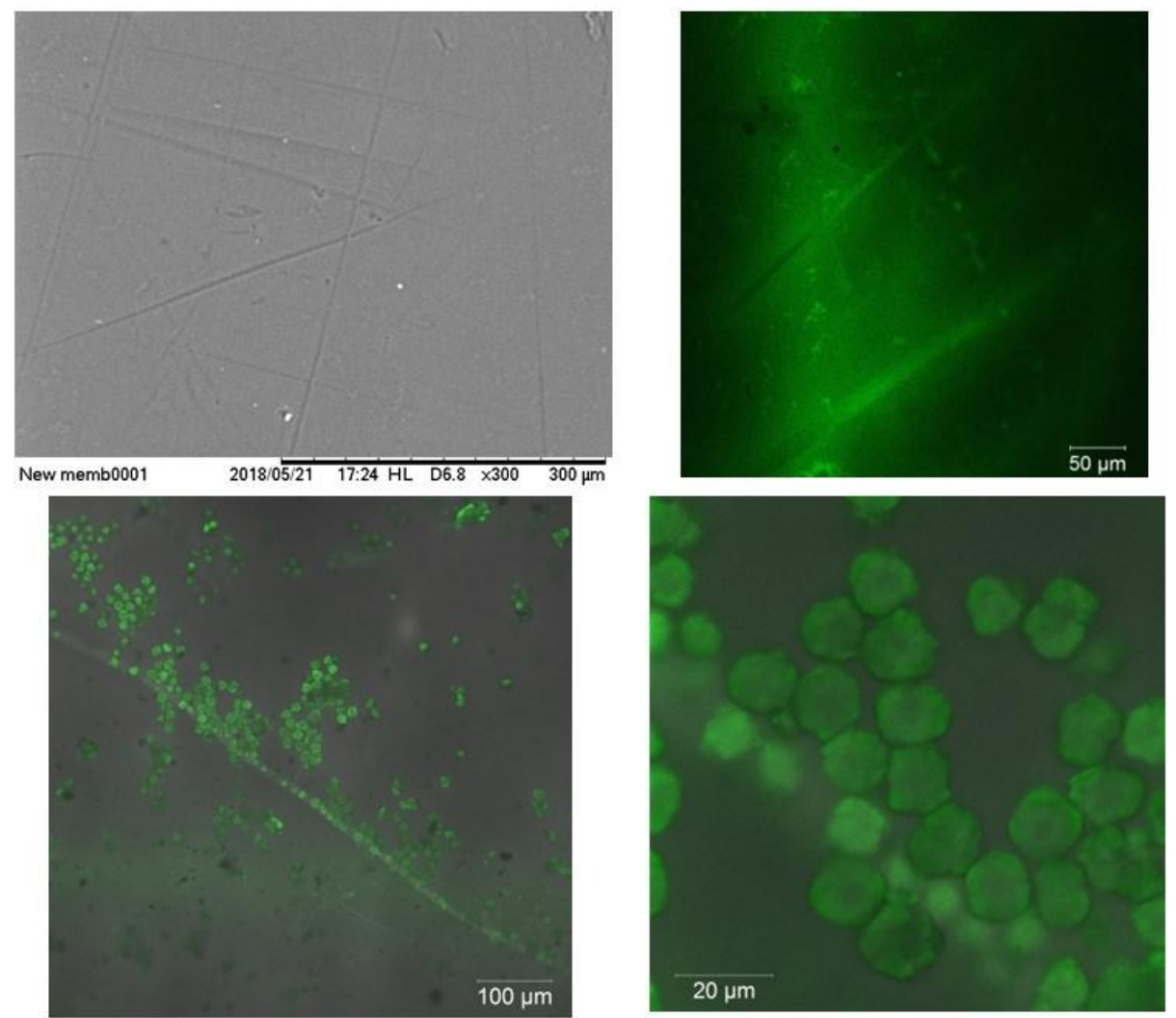

Figure 14. SEM (a) and fluorescent (b, c, d) images of reverse osmotic membrane CSM 1812$100 \mathrm{GPD}$ after PA-F1 aqueous solution $\left(25 \mathrm{mg} \cdot \mathrm{dm}^{-3}\right)$ permeation (b), and after a calcium carbonate-sulfate - PA-F1 brine treatment (c, d). Data obtained by A. Andrianov and A. Ryabova.

\section{Acknowledgments}

This review was prepared with support of the Russian Science Foundation, Project No. 1979-10220.

\section{References}

1. M. Oshchepkov and K. Popov, Fluorescent Markers in Water Treatment, Desalination and Water Treatment, 2018, Eds.: M. Eyvaz and E. Yüksel, London, IntechOpen, pp. 311-331. doi: 10.5772/intechopen.76218

2. G. Liu, M. Xue and Y. Zhou, Linear-dendritic block copolymer containing fluorescent groups: an effective and environmentally benign inhibitor for calcium carbonate. Tenside, Surfactants, Deterg., 2018, 55, no. 1, 56-64.

3. D.W. Fong and J.E. Hoots, Fluorescent group-tagged acrylic polymers and their synthesis by post-polymerization (trans)amidation, USA Patent, 1992, EP 475602 A2 19920318 ; US5128419. 
4. B.E. Moriarty, J.E. Hoots, M. Wei, D.P. Workman and J.P. Rasimas, Fluorescent monomers and polymers containing same for use in industrial water systems, PCT Int. Appl., 2001, WO 2001044403 A1 20010621.

5. J.D. Morris, B.E. Moriarty, M. Wei, P.G. Murray and J.L. Reddinger, Fluorescent monomers and tagged treatment polymers containing same for use in industrial water systems, PCT Int. Appl., 2001, WO 2001081654 A1 20011101.

6. W.L. Whipple and P.G. Murray, Fluorescent monomers and tagged treatment polymers containing same for use in industrial water systems, USA Patent, 2002, 6344531.

7. B.E. Moriarty, M. Wei, J.E. Hoots, D.P. Workman and J.P. Rasimas, Fluorescent monomers and tagged treatment polymers containing same for use in industrial water systems, USA Pat., 2001, 6312644.

8. E. Hills and P. Chapon, Tagged scale inhibiting polymers, compositions comprising the same, and method for preventing or controlling scale formation, PCT Int. Appl., 2005, WO 2005000747 A2 20050106.

9. E. Hills and P. Chapon, Tagged scale inhibiting polymers, compositions comprised thereof and preventing or controlling scale formation therewith, USA Patent, 2011, US 7943058 B2 20110517.

10. L. Moore and L. Clapp, Tagged scale inhibitor compositions and methods of inhibiting scale for oil field application, USA Pat. Appl. Publ., 2012, US 20120032093 A1 20120209.

11. L. Moore and L. Clapp, Tagged scale inhibitor compositions and methods of inhibiting scale for oil field application, USA Patent, 2015, 9309137.

12. S. Toivonen and V. Nuutinen, Tagged scale inhibiting polymer compositions and methods of inhibiting scale formation, PCT Int. Appl., 2014, WO 2014009445 A1 20140116.

13. H. Zheng, Method for measuring polymer concentration in industrial water systems using an indicator dye based on an acridine compound, USA Pat., 2017, 10184927; PCT Int. Appl., 2016, WO 2016161247 A1 20161006.

14. J. Wegner, E. Brown, J. Atkins, P. Zinn, R. Walicki and L. Hu, Use of fluorescent polymers in marking compositions for the diagnostic determination of cleaning performance, USA Patent, 2017, 10155058; USA Pat. Appl. Publ., 2016, US 20160002525 A1 20160107.

15. S.D. Kamagurov, N.E. Kovaleva, M.S. Oshchepkov, K.I. Popov, S.V. Tkachenko and E.S.Starkova, Fluorophor and method for obtaining salt inhibitor containing fluorophor as fluorescent mark, RF Patent, 2017, RU 2640339 C2 20171227 (in Russian).

16. G. Lijun and F. Jiuying, Fluorescent labeling polyaspartic acid scale inhibitor and preparation method thereof, PRC Patent, 2013, CN102910746B.

17. H. Dong, W. Wu, F. Wang and J. Yang, On-line fluorescence detection system based on fluorescence-labeled anti-scale and corrosion inhibitor, PRC Patent, 2016, CN 105388130 A 20160309. 
18. Y. Zhang, Q. Zhang, Y. Shi, W. Lei, M. Xia and F. Wang, Fluorescence labeling acrylic acid-sodium acrylic sulphonate co-polymer water treatment agent and preparation method thereof, PRC Patent, 2010, CN101381168B.

19. Y. Zhou, H. Wang, G. Liu, J. Huang, Q. Yao, Ling, C. Lei, L. Ke, Y. Liu, Y. Tu and $\mathrm{W}$. Wu, Environmentally-friendly corrosion and scale inhibitor of fluorescencelabelled polyether carboxylate, Faming Zhuanli Shenqing, 2013, CN 103159333 A 20130619.

20. N. Wei, Fluorescence-labelled tracer and preparation method thereof. Faming Zhuanli Shenqing, 2012, CN 102533256 A 20120704.

21. K. Popov， M. Oshchepkov， S. Kamagurov， S. Tkachenko， Yu. Dikareva and G. Rudakova, Synthesis and properties of novel fluorescent-tagged polyacrylate-based scale inhibitors, J. Appl. Polym. Sci., 2017, 134, 45017. doi: 10.1002/APP.45017

22. Z. Shen, X. Zhi and P. Zhang, Preparation of fluorescent polyaspartic acid and evaluation of its scale inhibition for $\mathrm{CaCO}_{3}$ and $\mathrm{CaSO}_{4}$, Polym. Adv. Technol., 2017, 28, 367-372. doi: 10.1002/pat.3897

23. G. Liu, M. Xue and Y. Zhou, Fluorescent-tagged block copolymer as an effective and green inhibitor for calcium sulfate scales, Russ. J. Appl. Chem., 2016, 89, 1861-1868. doi: $10.1134 /$ S1070427216110185

24. K. Wu, F. Chen, Y. Liu and J. Luo, Preparation and properties of $\beta$-cyclodextrins polymer used as calcium carbonate scale inhibitor containing fluorescent groups, Res. Chem. Intermed., 2014, 41, 7617-7630. doi: 10.1007/s11164-014-1847-7

25. H. Wang, Y.Zhou, Q. Yao and W. Sun, Calcium sulfate precipitation studies with fluorescent-tagged scale inhibitor for cooling water systems, Polym. Bull., 2015, 72, 2171-2188. doi: 10.1007/s00289-015-1396-2

26. J. Feng, L. Gao, R. Wen, Y. Deng, X. Wu and S. Deng, Fluorescent polyaspartic acid with an enhanced inhibition performance against calcium phosphate, Desalination, 2014, 345, 72-76. doi: 10.1016/j.desal.2014.04.019

27. G. Liu, J. Huang, Y.Zhou, Q. Yao, H. Wang, L. Ling, P. Zhang, K. Cao, Y. Liu, W. Wu and W. Sun, Int. J. Polym. Mater. Polym. Biomater., 2013, 62, 678-685. doi: 10.1080/00914037.2013.769226

28. K. Du, Y. Zhou, L. Dai and Y. Wang, Preparation and properties of polyether scale inhibitor containing fluorescent groups, Int. J. Polym. Mater. Polym. Biomater., 2008, 57, 785-796. doi: 10.1080/00914030801962988

29. K. Du, Y. Zhou, L. Wang and Y. Wang, Fluorescent-tagged no phosphate and nitrogen free calcium phosphate scale inhibitor for cooling water systems, J. Appl. Polym. Sci., 2009, 113, 1966-1974. doi: 10.1002/app.30213

30. H. Zhang, L. Zhao, S. Sun, Z. Cai, J. Zhang, X. Han, X. Guo, M. Cui and D. Xie, A study on fluorescence properties of carboxymethyl-quaternary ammonium oligochitosan and its performances as a tracing agent, Water Sci. Technol., 2016, 74, no. 10, 24272436. 
31. H. Wang, Y. Zhou, Q. Yao, S. Ma, W. Wu and W. Sun, Synthesis of fluorescenttagged scale inhibitor and evaluation of its calcium carbonate precipitation performance, Desalination, 2014, 340, 1-10. doi: 10.1016/j.desal.2014.02.015

32. B. Zhang, D. Zhou, X. Lu, Y. Xu and Y. Ciu, Synthesis of polyaspartic acid/3-amino$1 H$-1,2,4-triazole-5-carboxylic acid graft copolymer and evaluation of its corrosion inhibition and scale inhibition performance, Desalination, 2013, 327, 32-38. doi: $10.1016 /$ j.desal.2013.08.005

33. Y. Xu, B. Zhang, L. Zhao and Y. Ciu, Synthesis of polyaspartic acid/3-aminoorotic acid graft copolymer and evaluation of its scale inhibition and corrosion inhibition performance, Desalination, 2013, 311, 156-161. doi: 10.1016/j.desal.2012.11.026

34. L.-J. Gao, J.-Y. Feng, B. Jin, Q.-N. Zhang, T.-Q. Liu, Y.-Q. Lun, and Z.-J. Wu, Carbazole and hydroxy groups-tagged poly(aspartic acid) scale inhibitor for cooling water system, Chem. Lett., 2011, 40, 1392-1394. doi: 10.1246/cl.2011.1392

35. K. Gawlitza, W. Wan, S. Wagner, K. Rurack, Fluorescent Molecularly Imprinted Polymers, in Advanced Molecularly Imprinting Materials, 2016, Eds.: A. Tiwari, L. Uzun, Scrivener Publishing LLC, 89-128.

36. A. Zhang, Y. Zhou, Q. Yao, T. Wang, J. Li, Y. Chen, J. Pan, S. Liang, Q. Nan, M. Zhang, et al., Inhibition of calcium scales by a fluorescent-tagged and polyetherbased polycarboxylate scale inhibitor for cooling water systems, Desalin. Water Treat., $2017, \mathbf{5 9}, 114-122$.

37. M. Oshchepkov, S. Kamagurov, S. Tkachenko, A. Ryabova and K. Popov, An Insight into the Mechanisms of the Scale Inhibition. A Case Study of a Novel Task-specific Fluorescent-tagged Scale Inhibitor Location on Gypsum Crystals, ChemNanoMat, 2019, 5, 586-592. doi: 10.1002/cnma.201800660

38. A. Yuchi, Y. Gotoh and S. Itoh, Potentiometry of effective concentration of polyacrylate as scale inhibitor, Anal. Chim. Acta, 2007, 594, 199-203.

39. V.E. Kalinina, V.A. Isaeva, Turbidimetric determination of polyacrylates, Izv. Vyssh. Uchebn. Zaved., Khim. Khim. Tekhnol., 1991, 34, no. 11, 68-71 (in Russian).

40. J. Pennington, An overview of alternative approaches to the development of monitoring methods for scale inhibitors in oilfield produced waters, Spec. Publ. - R. Soc. Chem. (Chem. Oil Ind.), 1988, 67, 108-120.

41. J. Hen, Method for monitoring polyacrylic scale inhibitor content. PCT Int. Appl., 1990, WO 9004159 A1 19900419.

42. R.R. Myers, J.E. Fink, Method for the colorimetric determination of polycarboxylates in aqueous systems, USA Patent, 1990, US4894346A.

43. B. Nowack, Environmental chemistry of phosphonates, Water Res., 2003, 37, 2533-2546.

44. C.K. Schmidt and H.-J. Brauch, Analysis of Aminopolycarboxylates and Organophosphonates, in Biogeochemistry of Chelating Agents, Eds.: B. Nowack, J.M. VanBriesen, ACS, N.Y., 2005, 76-97. 
45. K.I. Popov, N.E. Kovaleva, G.Ya. Rudakova, S.P. Kombarova and V.E. Larchenko, Recent State-of-the-Art of Biodegradable Scale Inhibitors for Cooling Water Treatment Applications (Review), Therm. Eng., 2016, 63, 122-129.

46. D. Hasson, H. Shemer and A. Sher, State of the art of friendly "green" scale inhibitors: a review article, Ind. Eng. Chem. Res., 2011, 50, 7601-7607.

47. H. Zhang, Z. Cai, X. Jin, D. Sun, D. Wang, T. Yang, J. Zhang and X. Han, Preparation of modified oligochitosan and evaluation of its scale inhibition and fluorescence properties, J. Appl. Polym. Sci., 2015. 132, 42518. doi: 10.1002/app.42518

48. J. Detering, B. Urtel, H. Weber, R. Ettl, T. Gaedt, E. Heintz, T. Bastigkeit, T. Eiting and D. Sendor-Mueller, Copolymers containing carboxylic acid groups, sulphonic acid groups and polyalkylene oxide groups as anti-scaling additive to washing and cleaning agents, Russ. Patent, 2016, RU2574395.

49. J. Detering, B. Urtel, S. Nied and E. Heintz, Low-Molecular, Phosphorus-containing polyacrylic acids and use thereof as scale inhibitors in water supply systems, Russ. Patent, 2016, RU2593591C2.

50. E. Hills, S. Touzet and B. Langlois, Stimulating Oilfields Using Different ScaleInhibitors, USA Patent, 2007, US7703516B2.

51. H. Shuzhong, Z. Weisheng, R. Yu, T. Houkai, M. Xiangyan, Y. Longxin, X. Wu and J. Wang, Preparation method of acrylic polymer with fluorescence characteristic. Agent for water treatment containing a polymer for water treatment and a process for producing said polymer, PRC Patent, 2015, CN103242476B.

52. K. Mayumi and K. Norimasa, Agent for water treatment containing a polymer for water treatment and a process for producing said polymer, USA Patent, 1997, US5635575A.

53. B.R. Zhang, L. Zhang, F.T. Li, W. Hu, and P.M. Hannam, Testing the formation of Ca-phosphonate precipitates and evaluating the anionic polymers as Ca-phosphonate precipitates and $\mathrm{CaCO}_{3}$ scale inhibitor in simulated cooling water, Corros. Sci., 2010, 52, 3883-3890.

54. W.O.S. Doherty, C.M. Fellows, S. Gorjian, E. Senogles, and W.H. Cheung, Inhibition of calcium oxalate monohydrate by poly(acrylic acid)s with different end groups, J. Appl. Polym. Sci., 2004, 91, 2035-2041.

55. G. Liu, J. Huang, Y. Zhou, Q. Yao, Y. Yang, L. Ling, H. Wang, W. Wu, W. Sun and $\mathrm{Z}$. Hu, Fluorescent-tagged acrylic acid-allylpolyethoxy carboxylate copolymer as a green inhibitor for calcium phosphate in industrial cooling systems, Des. Monomers Polym., 2013, 16, 89-98.

56. H. Wang, Y. Zhou, Q. Yao, G. Liu, J. Huang, Q. Yao, S. Ma, K. Cao, Y. Liu, W. Wu, $\mathrm{W}$. Sun, et al., Investigation of calcium carbonate precipitation in the presence of fluorescent-tagged scale inhibitor for cooling water systems, Desalin. Water Treat., 2015, 53, 3491-3498. doi: 10.1080/19443994.2013.873353

57. L. Moore and L. Clapp, Tagged scale inhibitor compositions and methods of inhibiting scale, USA Patent, 2015, US8980123B2. 
58. W. Ying, L. Peng, F. Jiajun, L. Xiaodong, L. Zhuo and L. Xuelong, Preparation method of acrylic polymer with fluorescence characteristic, PRC Patent, 2015, CN103482777B.

59. R.R. Mittapalli, S.S.R. Namashivaya, A.S. Oshchepkov， E. Kuczyńska and E.A. Kataev, Design of anion-selective PET probes based on azacryptands: The effect of pH on binding and fluorescence properties, Chem. Commun., 2017, 53, 4822-4825. doi: $10.1039 / \mathrm{C} 7 \mathrm{CC} 01255 \mathrm{~A}$

60. A.S. Oshchepkov, R.R. Mittapalli, O.A. Fedorova and E.A. Kataev, Naphthalimidebased polyammonium chemosensors for anions: Study of binding properties and sensing mechanisms, Chem. Eur. J., 2017, 23, 9657-9665. doi: 10.1002/chem. 201701515

61. A.S. Oshchepkov, M.S. Oshchepkov, A.N. Arkhipova, P.A. Panchenko and O.A. Fedorova, Synthesis of 4-nitro-N-phenyl-1,8-naphthalimide annulated to thia- and azacrown ether moieties, Synthesis, 2017, 49, 2231-2240. doi: 10.1055/s-00361588712

62. M.V. Oshchepkova, M.S. Oshchepkov, O.A. Fedorova, Yu.V. Fedorov and V.I. Lozinskii, New copolymer gels based on N,N-dimethylacrylamide and crowncontaining allyl derivative of 1,8-naphthalimide as optical sensors for metal cations in an organic medium, Dokl. Phys. Chem., 2017, 476, 181-185. doi: $10.1134 / \mathrm{S} 0012501617100050$

63. M.V. Oshchepkova, A.S. Oshchepkov, O.E. Zaborina, O.A. Fedorova, Yu.V. Fedorov and V.I. Lozinsky, Fluorescent cryogels based on copolymers of N,N-dimethylacrylamide and allyl derivatives of 1,8-naphthalimide, Polym. Sci., Ser. $B$, 2015, 57, 631-637. doi: 10.1134/ S1560090415060159

64. M. Hollauf, M. Cajlakovič, M. Tscherner, S. Köstler, A.C. Knall and G. Trimmel, Synthesis and characterization of naphthalimide-functionalized polynorbornenes, Monatsh. Chem., 2016, 148, no. 1, 121-129.

65. M.K. Sinolitskii, N.I. Atrakhimovich, S.P. Voronin, T.V. Gerasimova, V.G. Debabov, O.Yu. Klygina, S.V. Kozulin, G.A. Larikova, T.E. Leonova, E.E. Polunina, et al., Method of L-aspartic acid producing, Russ. Patent, 2001, RU 2174558 C1 20011010.

66. A. Martinod, M. Euvrard, A. Foissy and A. Neville, Progressing the understanding of chemical inhibition of mineral scale by green inhibitors, Desalination, 2008, 220, no. 1-3, 345-352. doi: 10.1016/j.desal.2007.01.039

67. L.A. Perez and S.M. Kessler, Novel calcium phosphate scale Inhibitor, in: Water Soluble Polymers, Eds. Z. Amjad, 2002, Kluwer Academic Publishers, New York, Boston, Dordrecht, London, Moscow.

68. J. Hoots, C. Burkart and S. Paulson, Tracing process problems, Chem. Eng. Prog., 2002, 98, no. 4, 66-70. 
69. L.P. Koskan and A.R.Y. Meah, Production of polyaspartic acid from maleic acid and ammonia, U.S. (1994), US 5373088 A 19941213, Europ. Patent, 1995, EP0745103B1; L.P. Koskan and A.R.Y. Meah, Production of polysuccinimide and polyaspartic acid from maleic anhydride and ammonia. U.S. (1994), US 5296578 A 19940322.

70. L.P. Koskan and A.R.Y. Meah, Production of high-molecular-weight polysuccinimide and high-molecular-weight polyaspartic acid from maleic anhydride and ammonia, USA Patent, 1993, US 5219952 A 19930615; USA Patent, 1993, US5296578.

71. L. Gao and J. Feng, Fluorescence-labeled polyaspartic acid scale inhibitor and its preparation method, PRC Patent, 2013, CN 102910746 A 20130206.

72. L. Gao, J. Feng, B. Jin, Q. Zhang, T. Liu, Y. Lun and Z. Wu, Carbazole and hydroxy groups-tagged poly(aspartic acid) scale inhibitor for cooling water systems, Chem. Lett., 2011, 40, 1392-1394.

73. Y. Gao, L. Fan, L. Ward and Z. Liu, Synthesis of polyaspartic acid derivative and evaluation of its corrosion and scale inhibition performance in seawater utilization, Desalination, 2015, 365, 220-226.

74. A.L. Kavitha, T. Vasudevan, H.G. Prabu, Evaluation of synthesized antiscalants for cooling water system application, Desalination, 2011, 268, 38-45. doi: 10.1016/j.desal.2010.09.047

75. T. Sakamoto, A. Ojida and I. Hamachi, Molecular recognition, fluorescence sensing, and biological assay of phosphate anion derivatives using artificial $\mathrm{Zn}$ (II)-Dpa complexes, Chem. Commun., 2009, 2, 141-152. doi: 10.1039/B812374H

76. Y. Sun, C. Zhong, R. Gong and E. Fu, A highly selective fluorescent probe for pyrophosphate in aqueous solution, Org. Biomol. Chem., 2008, 6, 3044-3047. doi: 10.1039/B808422J

77. V. Kubíček， J. Rudovsky， J. Kotek， P. Hermann， L. Vander Elst， R.N. Muller, Z.I. Kolar, H. Th. Wolterbeek, J.A. Peters and I. Lukes, A bisphosphonate monoamide analogue of DOTA: a potential agent for bone targeting, J. Am. Chem. Soc., 2005, 127, 16477-16485. doi: $10.1021 / \mathrm{ja} 054905 \mathrm{u}$

78. T. Vitha, V. Kubicek, P. Hermann, L. Vander Elst, R.N. Muller, Z.I. Kolar, H.T. Wolterbeek, W.A.P Breeman, I. Lukes and J.A. Peters, Lanthanide(III) complexes of bis(phosphonate) monoamide analogues of DOTA: bone-seeking agents for imaging and therapy, J. Med. Chem., 2008, 51, 677-683. doi: 10.1021/jm7012776

79. L. Zhang, T. Navaratna, J. Liao and G.M. Thurber, Dual-Purpose Linker for Alpha Helix Stabilization and Imaging Agent Conjugation to Glucagon-Like Peptide-1 Receptor Ligands, Bioconjugate Chem., 2015, 26, 329-337.

80. M. Ethirajan, Y. Chen, P. Joshi and R.K. Pandey, The role of porphyrin chemistry in tumor imaging and photodynamic therapy, Chem. Soc. Rev., 2011, 40, 340-362. doi: 10.1039/B915149B

81. H. Wang, Y.Zhou, Q. Yao and W. Sun, Calcium sulfate precipitation studies with fluorescent-tagged scale inhibitor for cooling water systems, Polym. Bull., 2015, 72, 2171-2188. doi: 10.1007/s00289-015-1396-2 
82. T.E. McNeel, M.S. Whittemore, R.A. Clark and J.J. Grabowicz, Tagged polymers, water treatment compositions, and methods of their use in aqueous systems, WIPO (PCT), 2013, WO2013025332 A1 20130221.

83. K. Popov, G. Rudakova, V. Larchenko, M. Tusheva, S. Kamagurov, J. Dikareva and N. Kovaleva, Comparative Performance Evaluation of Some Novel "Green" and Traditional Antiscalants in Calcium Sulfate Scaling, Adv. Mater. Sci. Eng., 2016, 1, no. 3, 1. doi: $\underline{10.1155 / 2016 / 7635329}$

84. R.W. Sabnis, Handbook of Fluorescent Dyes and Probes, 2015, 1st ed., Hoboken, NJ, USA, John Wiley \& Sons, Inc. doi: 10.1002/9781119007104

85. T.-H. Tran-Thi, C. Prayer, Ph. Millie, P. Uznanski and J.T. Hynes, Substituent and Solvent Effects on the Nature of the Transitions of Pyrenol and Pyranine. Identification of an Intermediate in the Excited-State Proton-Transfer Reaction. J. Phys. Chem. A, 2002, 106, 2244-2255. doi: 10.1021/jp0125606

86. NALCO Company official web-site https://www.ecolab.com/nalco-water.

87. J.E. Hoots, B.E. Hunt, Fluorescent tracers - chemical treatment monitors. US Patent, 1988, 4,783,314 Nalco Chemical Company.

88. B.E. Moriarty, W.H. Hoy, D.A. Johnson, J.J. Hickey, J.E. Hoots, E. John, Continuous on-stream monitoring of cooling tower water, Eur. Pat. Appl., 1990, EP 365815 A1 19900502, US Patent, 1991, 4,992,380, Nalco Chemical Company.

89. G. Reggiani and P. Young, TRASAR ${ }^{\circledR}$ Technology - a Review and Comparison, Eastern Technologies, Inc., https://ru.scribd.com/document/322931480/AWT-TrasarPaper-Final

90. Y. Xie, X. Wang and M. Wei, Application of fluorescent dyes to trace and quantify chemical Dosage in industrial wastewater, US Patent, 2013, WO 2013/134617 Al 20130912.

91. S. Kamagurov, M. Oshchepkov, D.G. Nazarov, S. Mancini, K. Popov, S. Tkachenko and G. Rudakova, Performance of a novel fluorescent-tagged polyacrylate at a cooling tower test facility: a bench-scale and industrial-scale evaluation, Int. J. Corros. Scale Inhib., 2018, 7, no. 3, 418-426. doi: 10.17675/2305-6894-2018-7-3-11

92. T.A. Hoang, Mechanisms of Scale Formation and Inhibition, in Mineral Scales and Deposits, Scientific and Technological Approaches, 2015, Eds.: Z. Amjad and K. Demadis, 1st Edition, Elsevier, 47-83.

93. Y.M. Al-Roomi and K.F. Hussain, Potential kinetic model for scaling and scale inhibition mechanism, Desalination, 2016, 393, 186-195.

94. L. Liu and A. He, Research progress of scale inhibition mechanism, Adv. Mater. Res., 2014, 955-959, 2411-2414.

95. G. Zhang, J. Ge, M. Sun, B. Pan, T. Mao and Z. Song, Investigation of scale inhibition mechanisms based on the effect of scale inhibitor on calcium carbonate crystal forms, Sci. China, Ser. B: Chem., 2007, 50, 114-120. 
96. K. Popov， M. Oshchepkov， E. Afanas'eva， E. Koltinova， Yu. Dikareva and H. Rönkkömäki, DLS study of a phosphonate induced gypsum scale inhibition mechanism using indifferent nanodispersions as the standards of a light scattering intensity comparison, Colloids Surf., A, 2019, 560, 122-129. doi: 10.1016/j.colsurfa.2018.10.015

97. K.I. Popov, M.S. Oshchepkov, N.A. Shabanova, Yu.M. Dikareva, V.E. Larchenko, and E.Ya. Koltinova, DLS study of a phosphonate induced gypsum scale inhibition mechanism using indifferent nanodispersions as the standards of a light scattering intensity comparison, Int. J. Corros. Scale Inhib., 2018, 7, 9-24. doi: 10.17675/2305$\underline{6894-2018-7-1-2}$ 